\title{
Atualização do sistema de suporte à decisão para outorga de uso de recursos hídricos do estado da Bahia
}

\author{
Update of the decision support system for water permit in \\ the state of Bahia
}

\begin{abstract}
Gisele Oliveira Mota da Silva ${ }^{1}$ (D), Yvonilde Dantas Pinto Medeiros ${ }^{1}$ (D), Andrea Sousa Fontes ${ }^{2}$ (D)
${ }^{1}$ Universidade Federal da Bahia - UFBA, Salvador, BA, Brasil. E-mails: gisele_oms@hotmail.com, yvonilde.medeiros@gmail.com

2Universidade Federal do Recôncavo da Bahia - UFRB, Cruz das Almas, BA, Brasil. E-mail: asfontes@gmail.com
\end{abstract}

Como citar: Silva, G. O. M., Medeiros, Y. D. P., \& Fontes, A. S. (2021). Atualização do sistema de suporte à decisão para outorga de uso de recursos hídricos do estado da Bahia. Revista de Gestão de Água da América Latina, 18, e8. https://doi.org/10.21168/rega.v18e8

RESUMO: Sistemas de Suporte à Decisão (SSD) são ferramentas que podem ser utilizadas na gestão de recursos hídricos. 0 órgão gestor de recursos hídricos do estado da Bahia utiliza dois SSDs para realizar os cálculos e armazenar as informações de outorgas concedidas para corpos hídricos superficiais, no entanto os mesmos apresentam problemas. Nesse contexto, o objetivo do presente trabalho é de propor a atualização do SSD para outorga de recursos hídricos superficiais no estado da Bahia, incluindo uma estratégia de mapeamento e proposição de melhorias ao Processo de Análise Técnica de Outorga. Para a proposta de melhoria deste processo de trabalho, utilizou-se a abordagem Business Process Management (BPM). Os resultados demonstraram que a maior parte das oportunidades de melhorias identificadas está relacionada com a possibilidade de automatização de tarefas com incorporação ao sistema computacional existente, o Sistema Estadual de Informações Ambientais e de Recursos Hídricos (SEIA). 0 modelo proposto representa ganhos em desempenho, produtividade e otimização das funções desempenhadas. Além disso, apresenta inovações de metodologia e procedimentos na utilização de um SSD para outorga de corpos hídricos superficiais, considerando experiências de sistemas existentes e adaptando-o à realidade local.

Palavras-chave: Gestão de Recursos Hídricos; Outorga de Direito de Uso de Recursos Hídricos; Sistema de Suporte à Decisão para Outorga.

ABSTRACT: Decision Support Systems (DSS) are tools that can be used in the management of water resources. The water agency of Bahia state uses two types of DSS to perform calculations and to store the information of water permits of surface water. However, these systems have problems. In this context, this study proposes to update the water permit of surface water Decision Support System of Bahia state, including a mapping strategy and a proposal of improvements to the Technical Water Permit Analysis Process. We built the proposal using Business Process Management (BPM). The results showed that most of the opportunities of improvement identified are related to the lack of tasks automation, that can be fixed through integration with the existing computer system, SEIA. This will increase the agility and reliability of the process. The proposed model also increases the performance and productivity, and optimizes some tasks performed. In addition, presents generic innovations in the methodology and procedures of a water permit of surface water DSS, considering experiences of existing systems and adapting it to the local reality.

Keywords: Management of Water Resources; Water Permit; Decision Support Systems for Water Permits.

\section{INTRODUÇÃO}

A Política Nacional de Recursos Hídricos (Brasil, 1997) estabelece que, para ter direito ao uso da água que seja passível de alterar a quantidade, qualidade ou regime do corpo hídrico, é necessário solicitar a outorga de direito de uso de recursos hídricos. Essa solicitação é submetida a uma análise pelo órgão gestor de recursos hídricos com relação ao atendimento aos critérios legais e técnicos, culminando no deferimento ou não do pedido. Em regra, são realizadas a análise documental e a

Recebido: 17/05/2021. Revisado: 20/07/2021. Aceito: 21/07/2021. 
análise técnica, sendo esta relacionada ao atendimento dos critérios de outorga, comparando-se a demanda do empreendimento com a vazão disponível para outorga.

No caso de outorgas superficiais, uma vazão de referência é tomada como base e estipulada uma porcentagem máxima de utilização por usuário e pelo conjunto de usuários até o ponto avaliado, visando à compatibilização dos usos e a manutenção de ecossistemas aquáticos. Em se tratando de captação, contabilizam-se as vazões que estão sendo retiradas e, no caso de lançamento de efluentes, as vazões que estão sendo utilizadas para diluir e depurar os poluentes.

De acordo com Silva et al (2017), apesar de o princípio da análise ser o mesmo, os órgãos gestores dos diferentes estados da federação e da União adotam metodologias diferentes na avaliação do pleito. Um exemplo disso são as metodologias utilizadas para avaliar os pleitos de outorga, que podem envolver o uso de um Sistema de Suporte a Decisão (SSD).

Os SSDs são sistemas computacionais que, a partir de variáveis pré-definidas e relacionadas com o objeto em questão, geram cenários que permitem comparar, analisar, simular e apoiar a seleção de alternativas (Heinzle et al., 2010).

A utilização de SSDs no gerenciamento de recursos hídricos tem objetivos diversos, podendo ser aplicadas para representar cenários hidrológicos de maneira simplificada, auxiliando a tomada de decisão e apresentando soluções para problemas neste contexto (COLLISCOHNN, 2014). De acordo Kharabsheh et al (2019), SSDs têm sido usados na gestão de recursos hídricos por serem capazes de capturar os diferentes fatores que influenciam nas decisões relacionadas a uma tarefa tão complexa.

Para Garcia et al (2018), a maior dificuldade na tomada de decisão na gestão de Recursos Hídricos está em situações onde ocorrem conflitos quanto ao uso. Dessa forma, ao escolher uma metodologia de análise para apoiar a decisão, além da integração entre os usos qualitativos e quantitativos, deve-se prever uma abordagem otimizada, sendo possível reconhecer pontos críticos e determinar soluções que garantam a segurança hídrica da bacia como um todo.

$\mathrm{Na}$ aplicação em processos de outorgas, estes sistemas têm capacidade de automatizar as etapas da análise, indo ao encontro das tendências da chamada "Quarta Revolução ou Revolução Tecnológica" ou "Indústria 4.0", onde se observa a transformação das relações entre as pessoas e os meios de produção e o papel do capital humano totalmente integrados com a tecnologia, por meio da automatização das formas e processos de trabalho (Schwab, 2016). Espera-se com isso que as atividades humanas sejam, em sua maior parte, desenvolvidas com a finalidade de pensar, aprimorar e orientar a execução dos processos organizacionais e não operacionalizar processos.

Um dos pontos vantajosos para a utilização de SSDs na avaliação de pleitos de outorga foi apresentado por Pereira et al (2012) e consiste na integração entre a base de dados geográficos e a metodologia de análise de pleitos de outorgas, visto que a avaliação sem essa utilização muitas vezes envolve procedimentos manuais, como cálculos em planilhas, análise de mapas e geração de relatórios.

É possível evidenciar avanços com a proposição de modelos de SSDs para a gestão de recursos hídricos, como aqueles desenvolvidos por Oliveira e Zeilhofer (2017) e Garcia et al (2018). Os dois têm o objetivo comum de apoiar a decisão em processos de outorga de uso de recursos hídricos e apresentam modelos de otimização, sendo que o sistema desenvolvido por Oliveira e Zeilhofer (2017) contém um módulo para solução de conflitos pelo uso da água. O SSD desenvolvido por Garcia et al (2018) tem o objetivo principal de identificar os melhores locais para se investir em tratamento de efluentes, minimizando custos para implantação e maximizando os usos quantitativos. Esta solução é obtida com a geração de cenários de otimização do uso da água para a bacia ao integrar a análise quantitativa com a qualitativa, custos de implantação de soluções de descontaminação e critérios estabelecidos para o uso da água.

Julian etal. (2015) desenvolveram e aplicaram um sistema de suporte à decisão para gerenciamento de reservatórios para avaliar a planície de inundação e os benefícios e compensações socioeconômicas das alternativas de manejo de reservatórios na bacia hidrográfica do rio Connecticut nos Estados Unidos. Este sistema foi desenvolvido em uma associação entre The Nature Conservancy (TNC) e o Exército dos EUA, no Projeto de Rios Sustentáveis do Corpo de Engenheiros (USACE). Este SSD é capaz de quantificar a alteração hidrológica para identificar quais reservatórios têm o maior potencial para alcançar a gestão de ecossistemas com menores consequências para as atividades, como geração de energia hidrelétrica e controle de inundação.

Foram também identificados sistemas com aplicação direta na análise de processos de outorga nos órgãos gestores da União e dos estados brasileiros. 0 Quadro 1 apresenta o resumo das principais características destes sistemas, que serão descritos a seguir. 
Quadro 1: Resumo dos SSDs para outorga dos órgãos gestores

\begin{tabular}{|c|c|c|}
\hline DENOMINAÇÃO & DOMINIALIDADE & PRINCIPAIS CARACTERÍSTICAS \\
\hline \multirow{3}{*}{ SDO } & \multirow{3}{*}{ UNIÃO } & Muito material disponível \\
\hline & & Realiza integração quali-quantitativa \\
\hline & & Não é eficiente para cálculo de bacias detalhadas \\
\hline \multirow{2}{*}{ SIGO } & \multirow{2}{*}{ BAHIA } & Modelo ultrapassado - Excel \\
\hline & & Não realiza integração quali-quantitativa \\
\hline SOL & CEARÁ & $\begin{array}{c}\text { Sistema para uso interno do órgão gestor, a cada } \\
\text { usuário que intervenha no processo. Não foram } \\
\text { identificadas informações de detalhamento do modelo } \\
\text { utilizado. }\end{array}$ \\
\hline \multirow{2}{*}{ SCBH-ES } & \multirow{2}{*}{ ESPÍRITO SANTO } & $\begin{array}{l}\text { Mesma metodologia de balanço hídrico adotada pelo } \\
\text { SDO }\end{array}$ \\
\hline & & $\begin{array}{l}\text { Alimentado por equações de regionalização e } \\
\text { regularização de vazões }\end{array}$ \\
\hline \multirow[b]{2}{*}{ WEB OUTORGA } & \multirow[b]{2}{*}{ GOIÁS } & Formação, análise e emissão de outorga. \\
\hline & & $\begin{array}{l}\text { Sistema apresenta um mapa com as informações de } \\
\text { usuários existentes e disponibilidade hídrica, com } \\
\text { interpolação de dados feita pelo método de Krigagem. }\end{array}$ \\
\hline Siriema & MATO GROSSO DO SUL & $\begin{array}{l}\text { Mesma metodologia de balanço hídrico adotada pelo } \\
\text { SDO. Utilizado para solicitação, acompanhamento e } \\
\text { análise de processos de outorga. }\end{array}$ \\
\hline SIGERHPA & PARÁ & $\begin{array}{l}\text { Em desenvolvimento. Formação e análise de } \\
\text { processos, até a publicação da Portaria de Outorga }\end{array}$ \\
\hline SIOUT & RIO GRANDE DO SUL & $\begin{array}{l}\text { Além do módulo de análise tem módulo de cadastro de } \\
\text { condicionantes }\end{array}$ \\
\hline SADPLAN & SANTA CATARINA & $\begin{array}{c}\text { Calcula diferentes métodos de balanços hídricos - } \\
\text { cenários de interesse. }\end{array}$ \\
\hline \multirow{4}{*}{ SSD BH Web } & \multirow{4}{*}{ SÃO PAULO } & Atribuição de prioridades \\
\hline & & Alta eficiência para cálculo de bacias muito detalhadas \\
\hline & & $\begin{array}{l}\text { Interage com modelos de rede de fluxo e modelos de } \\
\text { qualidade da água. }\end{array}$ \\
\hline & & $\begin{array}{c}\text { Cálculos de balanço hídrico e a alocação da água de } \\
\text { forma otimizada }\end{array}$ \\
\hline SAD Outorga & TOCANTINS & $\begin{array}{l}\text { Sistema online apoiado em Sistemas Gerenciadores de } \\
\text { Bancos de Dados e um Servidor de Aplicações } \\
\text { Geográficas.O sistema ainda não está em } \\
\text { funcionamento por terem sido identificadas } \\
\text { inconsistências durante os testes. }\end{array}$ \\
\hline
\end{tabular}

Fonte: ANA (2013), Collischon (2014), Silva et al. (2017), Ceará (2008), IEMA (2013), Goiás (2019), Mato Grosso do Sul (2015), Pará (2017), Rio Grande do Sul (2018), Santa Catarina (2018), DAEE (2012), Naturantins (2018).

Para os rios de domínio da União, são utilizados o Sistema Federal de Regulação de Uso - REGLA e o Sistema de Suporte à Decisão para Outorga (SSDO). 0 controle do fluxo de outorgas é realizado no REGLA, sendo o SSDO responsável por comparar disponibilidades hídricas e demandas já existentes na bacia hidrográfica e fornecer informações necessárias para a análise da outorga solicitada (ANA, 2020). O SSDO foi denominado inicialmente de Sistema de Controle de Balanço Hídrico (SCBH) e proposto por Collischonn \& Lopes (2008). Em seguida, foi aperfeiçoado por Collischonn (2014) e denominado SDO. Este sistema funciona em linguagem PHP com banco de dados SQL Server e utiliza uma base geográfica ottocodificada. 0 balanço hídrico entre demandas e disponibilidade hídrica é feito por trechos de rio, ou seja, para cada trecho, há uma vazão de referência associada. Cabe destacar que utilizando esta metodologia, dentro de um mesmo trecho, não é possível distinguir qual usuário está à montante e à jusante. Tudo se passa como se todos os usuários estivessem no exutório do trecho (COLLISCHONN, 2014). O REGLA teve sua operação iniciada em novembro de 2017 e, desde então, considera como dados de demanda tanto os usuários das águas de domínio da União quanto de domínio estadual (ANA, 2019). 
Seguindo a lógica de integração de dados, o órgão gestor do estado do Rio de Janeiro, que já inseria seus dados de usuários de recursos hídricos no Cadastro Nacional de Usuários de Recursos Hídricos (CNARH), passou a adotar também o REGLA para gerir os seus processos de outorga e cobrança (INEA, 2019).

O SCBH desenvolvido por Collischonn (2014) foi utilizado como base pela equipe técnica do órgão gestor do estado do Espírito Santo para desenvolvimento do Sistema de Controle de Balanço Hídrico (SCBH-ES). Neste sistema é possível inserir, alterar ou excluir interferências, com a atualização do balanço hídrico a cada movimentação no sistema. Neste sistema são computados dois tipos de interferências: captação direta ou captação em barramento. Para o caso de captações em barramentos, é necessário inserir; além dos dados de vazão instantânea, quantidade de horas e dias de captação; o volume útil do barramento e a vazão a ser mantida à jusante do barramento (IEMA, 2013).

De acordo com IEMA (2013), os dados de disponibilidade hídrica utilizados no sistema SCBH-ES foram obtidos em estudos preexistentes que definiram equações de regionalização por regiões hidrologicamente homogêneas no estado. Para bacias hidrográficas não contempladas nos estudos, são realizadas correlações com dados de estações fluviométricas. Para captações em barramentos, é realizada a estimativa das curvas de regularização de vazões.

Já no estado do Ceará, as outorgas são avaliadas com apoio do Sistema de Outorga e Licença (SOL) que armazena as informações e interage com os técnicos dos setores envolvidos no processamento da outorga ou licença. Esse sistema de informação foi montado para receber alimentação de cada usuário que intervenha no processo até a fase final com a geração da portaria de outorga (CEARÁ, 2008, 2017).

O Sistema Imasul de Registros e Informações Estratégicas do Meio Ambiente (SIRIEMA) é utilizado pelo órgão gestor do estado do Mato Grosso do Sul para solicitação e acompanhamento de processos e avaliação de outorgas. 0 cálculo do balanço hídrico superficial realizado neste sistema segue a mesma metodologia descrita por Agência Nacional de Águas (2013) e Collischonn (2014), onde são calculados indicadores de comprometimento hídrico a cada nova inserção de uma interferência (captação superficial, captação em barramento e lançamento de efluentes) no sistema (MATO GROSSO DO SUL, 2015)

No estado do Pará, está em desenvolvimento o Sistema de Gestão de Recursos Hídricos do Pará - (SIGERHPA) pela Fundação de Desenvolvimento Científico da Universidade Federal de Lavras. A contratação tem ênfase na modernização dos procedimentos de outorga, que atualmente são feitos de forma manual, desde as fases iniciais, de protocolo de processos e recepção de documentos, passando por todas as fases de análise até a expedição dos atos autorizativos de uso de recursos hídricos. Além disso, espera-se que este sistema propicie ao órgão gestor de recursos hídricos uma visão geral da disponibilidade hídrica no Estado, facilitando a identificação de possíveis regiões de conflitos e o estabelecimento de políticas governamentais integradas (PARÁ, 2017).

No órgão gestor de recursos hídricos do estado do Rio Grande do Sul foi desenvolvido o Sistema de Outorga de Água (SIOUT) da Secretaria do Ambiente e Desenvolvimento Sustentável (SEMA-RS) por meio da contratação em 2015 da Fundação de Desenvolvimento Científico e Cultural (FUNDECC) da Universidade Federal de Lavras. Em 2016, foram implantadas as modalidades de cadastro de usuários (tanto para águas superficiais quanto para águas subterrâneas), Autorização Prévia e Dispensa de Outorga e em 30 de setembro de 2018 foi instituída a obrigatoriedade de utilização do SIOUT neste estado, para novas solicitações de outorga, dispensa de outorga, reserva de disponibilidade hídrica, autorizações prévias para perfuração de poços, regularização de usos de água, alvarás de obras de reservação de água, aprovações de plano de segurança de barragens, certificados de cadastro, defesas e recursos decorrentes de indeferimento dessas solicitações (RIO GRANDE DO SUL, 2018).

O Sistema de Apoio à Decisão para o Planejamento do uso dos Recursos Hídricos utilizado pelo órgão gestor de recursos hídricos de Santa Catarina, o SADPLAN, reúne informações acerca dos recursos hídricos superficiais e realiza o levantamento dos cenários hídricos, atual e futuro. Sua principal função é calcular balanços hídricos que equacionem a diferença entre a disponibilidade e as demandas hídricas, para cada trecho de drenagem de uma bacia hidrográfica utilizando base hidrográfica codificada através do método Otto Pfafstetter (SANTA CATARINA, 2018).

De acordo com Santa Catarina (2018), o SADPLAN calcula diferentes métodos de balanços hídricos para fornecer resultados que atendam cenários de interesse para a gestão de recursos hídricos. 0 primeiro deles considera que todos os usuários têm a mesma prioridade e a vazão mínima remanescente pode chegar a zero; o segundo considera as prioridades dos diferentes 
usuários de recursos hídricos e mantém a vazão remanescente natural; o terceiro considera o controle de qualidade da água, calculando indicadores de qualidade para que se estime o enquadramento real do corpo hídrico, com ou sem decaimento de poluentes.

Ainda há exemplos de SSDs para outorga que interagem com modelos de rede de fluxo e modelos de qualidade da água. Como exemplo, pode-se citar o OutorgaLS (Labsid, 2012) e o Sistema de Suporte da Decisão para Outorga de Uso da Água no Estado de São Paulo, SSD BH Web, desenvolvido pelo Departamento de Águas e Energia Elétrica de São Paulo (DAEE, 2012). Os dois sistemas apresentam características comuns, realizando, além dos cálculos de balanço hídrico, a alocação da água de forma otimizada.

O SSD BH Web está em constante atualização e atualmente engloba a avaliação de pleitos de outorga em mananciais subterrâneos e superficiais. O SSD BH Web utiliza o modelo LabSid AcquaNet (Porto et. al., 2003) atualizado com algoritmos mais eficientes, permite a atribuição de prioridades para atendimento das demandas individuais e em grupos e possui alta eficiência para cálculo de bacias muito detalhadas (DAEE, 2012).

O SSD BH Web utiliza a base geográfica ottocodificada e os usos pontuais (captações, lançamentos, transposições ou barramentos) são contabilizados no exutório de cada unidade de balanço. Este sistema foi desenvolvido integrado ao Sistema de Outorga Eletrônico (SOE), de forma a ser alimentado pelas informações fornecidas pelos usuários da água e que possa se integrar com os demais instrumentos da Política Estadual de Recursos Hídricos (DAEE, 2012).

Conforme apresentam Amaro e Alves (2019), o órgão gestor de recursos hídricos do estado de Rondônia está desenvolvendo uma ferramenta para auxiliar a tomada de decisão técnica na gestão de recursos hídricos por meio de uma parceria entre o Instituto de Pesquisa Econômica Aplicada (Ipea) e a ANA. Foi feita a escolha pelo modelo OutorgaLS (Labsid, 2012), que realiza, além dos cálculos de balanço hídrico, a alocação da água de forma otimizada.

O SAD Outorga apresentado por Naturantins (2018) foi desenvolvido como um sistema online apoiado em Sistemas Gerenciadores de Bancos de Dados e um Servidor de Aplicações Geográficas. No entanto, de acordo com Naturantins (2018), o sistema ainda não está em funcionamento por terem sido identificadas inconsistências durante os testes realizados pelos analistas do órgão gestor.

O Sistema Eletrônico de Cadastro e Solicitação de Outorga (Web Outorga) utilizado pelo órgão gestor de recursos hídricos do estado de Goiás realiza o fluxo de análise da outorga compreendendo desde a entrada das informações pelo usuário da água, Criação de uma Declaração de uso de recursos hídricos (DURH), emissão de Certificado de Dispensa de Outorga ou Validação como "Sujeita a Outorga". Quando o uso é passível de outorga a DURH fica disponível ao usuário para montagem de processo de outorga e quando o processo é formado, é analisado pelos técnicos utilizando o Web Outorga. Nesta etapa, é utilizado o banco de dados do sistema que apresenta um mapa com as informações de usuários existentes e disponibilidade hídrica, com interpolação de dados feita pelo método de Krigagem (GOIÁS, 2019).

No estado da Bahia, são utilizados dois SSDs para realizar os cálculos e armazenar as informações de outorgas concedidas: o Sistema de Gerenciamento de Controle de Outorga (SIGO) Captação e SIGO Efluentes, no entanto, estes sistemas apresentam problemas como a falta de integração entre os SSDs para análises superficiais de captação e lançamento, atraso tecnológico, fragilidade na segurança da informação, falta de transparência e a inexistência de conexão com o Sistema Estadual de Informaç̧ões Ambientais e de Recursos Hídricos (SEIA) (Silva et. al., 2017). Os SIGOS foram desenvolvidos na extinta Superintendência de Recursos Hídricos da Bahia (SRH), em planilha eletrônica Excel, onde cada rio principal das Regiões de Planejamento e Gestão das Águas (RPGAs) é representado por uma planilha que realiza os cálculos de balanço hídrico para o rio principal e seus afluentes com as contribuições computadas de montante para jusante (Silva et al. 2003). Além disso, nos SIGOs não consideram a integração quali-quantitativa, bem como as alterações sazonais na disponibilidade hídrica e nas retiradas de água, metodologia utilizada por outros órgãos gestores, principalmente em se tratando de uso para irrigação. De acordo com os resultados do estudo realizado por Ramos et al. (2017), a consideração da sazonalidade na concessão de outorgas para irrigação melhora o gerenciamento do uso da água, pois em períodos de maior disponibilidade hídrica é possível aproveitar melhor o uso e em épocas de menor disponibilidade hídrica, restringi-lo. Soma-se a isso a consideração feita pela ANA (2019) de que a utilização de vazões sazonais representa um risco menor de desatendimento da vazão outorgada, uma vez que a probabilidade de ocorrência de valores menores que a vazão de referência utilizada é menor, quando se consideram vazões mês a mês. 
Sendo assim, verifica-se que alguns dos órgãos gestores de recursos hídricos brasileiros já têm seus SSDs para outorga implantados, em funcionamento e adequados, porém, a maior parte deles não possuem ou têm sistemas que precisam de adequações. Por exemplo, ANA (2019) cita um dos problemas encontrados nas análises técnicas realizadas pela maior parte dos órgãos gestores estaduais: a não consideração das outorgas emitidas pelos demais órgãos gestores dos recursos hídricos na mesma bacia. Isso porque, quando a ANA passou a considerar os usos outorgados pelos estados no balanço hídrico calculado pelo SSDO, observou que, em algumas bacias, os limites de vazões disponíveis para outorga são superados, impedindo a emissão de outorgas, até mesmo renovações para usos regularizados já existentes ANA (2019).

Neste contexto, o presente trabalho tem como objetivo propor a atualização do Sistema de Suporte à Decisão para outorga no estado da Bahia, incluindo uma estratégia de mapeamento e proposição de melhorias ao Processo de Análise Técnica de Outorga.

\section{MATERIAL E MÉTODOS}

Como o objetivo da pesquisa é a atualização com proposição de melhorias a um processo de trabalho, utilizou-se a abordagem BPM (Business Process Management). BPM consiste em uma abordagem disciplinada para identificar, desenhar, executar, documentar, medir, monitorar, controlar e melhorar os processos de negócio, tendo como objetivo eliminar defeitos e desperdícios, aumentando a velocidade das entregas dos participantes para alcançar os resultados pretendidos (ABPMP, 2013). 0 recorte definido para a aplicabilidade das técnicas do BPM como estudo de caso foi a análise do pedido de outorga realizada pelos técnicos do órgão gestor do estado da Bahia, desde o momento do recebimento do processo em sua pauta de trabalho no SEIA até a finalização da análise com envio do processo para a Coordenação. O produto final deste trabalho é uma proposta de Mapeamento do Processo de Análise Técnica de Outorga do órgão gestor do estado da Bahia com orientações para a atualização do Sistema de Suporte à Decisão para Outorga de corpos hídricos superficiais. De acordo com a ABPMP (2013), a melhoria de processos envolve um ciclo de vida contínuo, podendo ser mapeadas utilizando o ciclo básico PDCA (Plan - planejamento, Do - execução, Check - verificação, Act - ação) difundido por Deming (1990). Desta forma, este trabalho se estruturou em quatro etapas, seguindo as diretrizes do PDCA, conforme esquematizado na Figura 1.

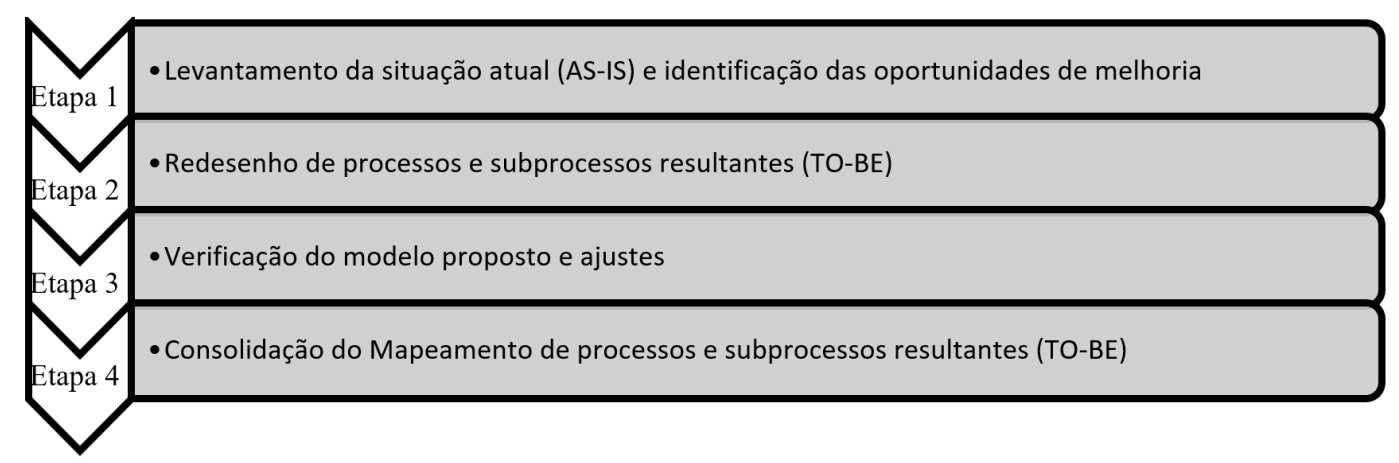

Figura 1: Etapas metodológicas. Fonte: As autoras.

Na abordagem BPM, o desenho do processo, representando a situação atual, é denominado de modo AS-IS (ABPMP, 2013).

Na Etapa 1 - Levantamento da situação atual (AS-IS) e identificação das oportunidades de melhoria buscou-se conhecer o problema e definir suas principais características. Para caracterizar o processo de Análise Técnica de Outorga com os SSDs existentes, optou-se pelo Mapeamento Analítico, visto que este tipo de mapeamento pode ser utilizado, tanto para melhorar o desempenho de um processo de trabalho quanto para subsidiar o desenho de um sistema informatizado pela equipe de Tecnologia da Informação (TI). O objetivo desta etapa foi realizar o levantamento de informações sobre: a) tipos de documentos utilizados no processo e procedimentos que regulam a atividade; b) tipos de 
sistemas e ferramentas utilizadas; c) responsáveis pelas atividades; d) dificuldades encontradas. A ABPMP (2013) descreve como algumas das atividades que podem ser usadas para coleta de informações para auxiliar no mapeamento dos processos de negócio, a pesquisa, a observação direta e simulação de atividades. A primeira técnica utilizada foi a de pesquisa em documentos do órgão gestor de recursos hídricos, como manuais de sistemas, procedimentos operacionais e documentações de projetos desenvolvidos. Em seguida foram utilizadas as técnicas de observação direta do processo e a simulação de atividades. A observação direta do processo foi realizada por meio das atividades dos executores da análise técnica de solicitações de outorga no estado da Bahia. Nesse processo também se buscou compreender como as ações executadas pelas interações humanas podem impactar nas atividades realizadas. Além disso, buscou-se listar as tarefas baseadas em Procedimentos Operacionais Padrão (POPs) bem definidos para avaliar quanto à potencialidade de serem automatizados no sistema a ser proposto. Por fim, foi realizada a simulação de atividades envolvidas no processo. A atividade de análise técnica foi simulada percorrendo cada uma das etapas envolvidas na análise técnica de um pleito de outorga, observando suas entradas, saídas e regras de negócio que definem o seu comportamento.

A modelagem do sistema identificado (AS-IS) foi realizada diretamente em Business Process Model and Notation (BPMN), utilizando o Software de Mapeamento Bizagi Modeler, registrada na forma de mapa de processo de trabalho. Cada atividade identificada foi desdobrada em mapas mais detalhados (subprocessos) até o nível considerado suficiente para realizar as análises que subsidiaram o desenvolvimento do produto proposto. A notação BPMN foi proposta pelo BPMI (Business Process Management Institute) no ano de 2004 e serve de apoio ao uso do BPM, para visualização dos processos por meio de representações gráficas, sendo possível realizar comparações entre o estado atual e, depois de feita a análise do processo, representar possíveis melhorias (ABPMP, 2013). Neste trabalho foi utilizada a versão 2.0 da notação BPMN, criada no ano de 2011 e disponibilizada por BPMN (2016).

Com o mapeamento finalizado, foi realizada a análise da situação atual e identificação das oportunidades de melhorias. Nesta etapa, buscaram-se oportunidades de melhorar o trabalho, torando-o mais ágil e eficiente.

Para isso, cada tarefa listada na atividade anterior foi detalhada no Software Bizagi e sintetizadas em quadros para os seguintes campos: a) Objetivo; b) Entradas; c) Descrição das Atividades; d) Saídas; e) Documentos de Referência e f) Oportunidades de Melhorias.

$\mathrm{Na}$ abordagem BPM, a situação proposta "deve ser" é conhecida como o modo TO-BE (Association of Business Process Management Professionals International, 2013).

A Etapa 2 - Redesenho de processos e subprocessos resultantes (TO-BE) contemplou as oportunidades de melhorias identificadas na Etapa 1. Algumas das soluções utilizadas no modelo proposto foram obtidas por meio de consulta à revisão bibliográfica realizada relacionada aos Sistemas de Suporte à Decisão utilizados para análise de pleitos de outorga ou que foram desenvolvidos para este fim. 0 redesenho do sistema foi realizado diretamente na Notação BPMN, utilizando o Software de Mapeamento Bizagi Modeler com o detalhamento de cada tarefa para os seguintes campos: a) Objetivo; b) Entradas; c) Descrição das Atividades; d) Saídas; e) Documentos de Referência. Em paralelo, foi produzido de um protótipo utilizando o software Microsoft Visual Studio contendo as telas do SEIA com as alterações propostas para representar o sistema visualmente.

De acordo com o Ciclo PDCA de Deming (1990), a etapa de verificação está presente em cada etapa da proposta de melhoria de processo. Dessa forma, a Etapa 3 - Verificação do modelo proposto e ajustes foi transversal às outras, sendo realizada durante a elaboração do modelo proposto, durante a elaboração do protótipo e em sua documentação, e também em constantes revisões das tarefas quanto à análise do êxito das soluções apresentadas no redesenho do processo.

Além disso, foi realizado o levantamento de oportunidades de melhorias futuras para tarefas que não foram atualizadas pelo modelo proposto, como forma de recomendações para projetos de melhoria de processos futuros. 
Com o objetivo de sanar dúvidas que surgiram nesta etapa quanto ao funcionamento do SSD proposto de forma integrada ao SEIA, foram realizadas duas reuniões com equipes de tecnologia do órgão gestor do estado da Bahia, conforme segue:

- Reunião em 15/10/2020 com equipe da Coordenação de Tecnologia da Informação e Comunicação (COTIC) do Inema.

- Reunião em 06/11/2020 com a equipe da Superintendência de Inovação e Desenvolvimento Ambiental (SIDA) da Secretaria de Meio Ambiente (SEMA).

Depois de realizados os ajustes necessários ao modelo proposto, foi realizada uma apresentação para um grupo focal do órgão gestor de recursos hídricos da Bahia, na busca de contribuições e validação do modelo proposto. 0 grupo foi formado por sete técnicos atuantes na Diretoria de Regulação, no Núcleo de Outorga, dois assessores técnicos da Diretoria Geral e seis membros das equipes de tecnologia da SEMA/SIDA e do Inema/COTIC que participaram das reuniões mencionadas. Foi preparado um questionário para verificar a aceitação do grupo especificamente com relação ao SSD para outorga proposto. 0 primeiro item do questionário solicitou a atribuição de notas de 1 (discordo totalmente) a 5 (concordo totalmente) para verificar a identificação dos participantes do grupo com relação às assertivas abaixo:

1. Este Sistema melhora desempenho e produtividade das funções desempenhadas pelo quadro técnico do órgão gestor.

2. Este sistema torna o processo de análise técnica mais rápido, simples, seguro e com menos falhas.

3. Este sistema dificulta a análise dos processos.

4. Este sistema substitui as funções realizadas pelo quadro técnico.

5. Com base na estrutura (física, humana, etc.) do órgão gestor, esta ferramenta será utilizada pelos técnicos do órgão.

O segundo item do questionário buscou registrar possíveis contribuições para o modelo apresentado, com a seguinte questão: "Identifica a necessidade de alterar e/ou complementar a proposta apresentada? Caso a reposta seja sim, escrever as suas sugestões".

Na Etapa 4 - Consolidação do Mapeamento de processos e subprocessos resultantes (TOBE), foi finalizado o mapeamento com os resultados da Etapa 3 com a descrição completa do sistema utilizando a funcionalidade de publicação do Bizagi Modeler, sendo adicionadas também as telas do protótipo produzido para o SSD proposto.

Além das etapas de mapeamento, foram descritas orientações para preparação e implantação da atualização proposta para o SSD para outorga com o detalhamento dos cálculos e bancos de dados (BD) a serem acessados e protótipos das telas do sistema. Foram sugeridas fases de implantação com os requisitos necessários para cada etapa.

\section{RESULTADOS E DISCUSSÃO}

\section{Etapa 1 - Levantamento da situação atual (AS-IS)}

O mapeamento inicial com base no método de observação direta do fluxo AS-IS do processo de Análise Técnica de Outorga é apresentado na Figura 4. A análise técnica se inicia no SEIA com o envio do processo de outorga pelo coordenador para a pauta do técnico responsável pela análise. Este mapeamento identificou todas as atividades realizadas pelo técnico durante a análise do processo, que inicia e finaliza no SEIA, mas que realiza interações com outros sistemas ou ferramentas durante o processo. 


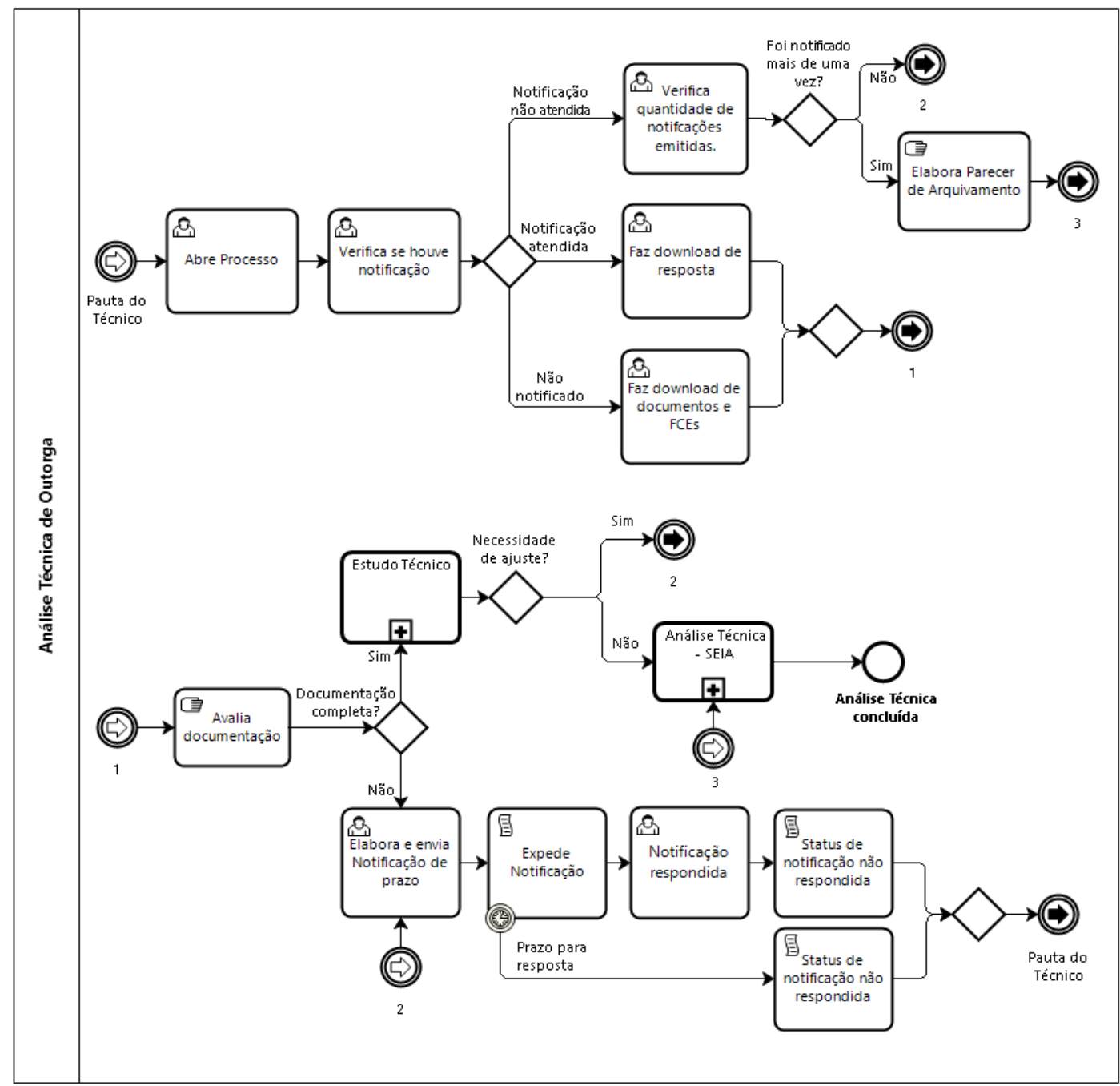

Figura 2: Fluxo "AS IS" do processo "Análise de Processo de Outorga". Fonte: As autoras.

Conforme pode ser verificado na Figura 2, foram mapeados subprocessos que representam etapas intermediárias do processo de Análise Técnica, onde foram necessários detalhamentos por haver subtarefas envolvidas, sendo eles:

a) Estudo Técnico (Figura 3) com subprocessos SIGO Captação (Figura 4) e SIGO Efluentes (Figura 5). b) Análise Técnica - SEIA (Figura 6).

Conforme pode ser verificado na Figura 3, o subprocesso Estudo Técnico foi representado de formas diferentes para processos de captação superficial e lançamento de efluentes por haver diferenças nas análises de usos insignificantes para os dois usos e por serem utilizados SSDs (SIGOs) distintos para cada um deles.

No caso da captação superficial, quando a análise é realizada para usos insignificantes (solicitações de dispensa de outorga), é feita apenas a análise de demanda, não sendo realizadas verificações de disponibilidade hídrica e balanço hídrico no ponto de captação. Dessa forma, os usos para captação superficial dispensados de outorga não são incluídos no SIGO Captação. Já nas análises dos usos para lançamento de efluentes, mesmo quando o uso é classificado como insignificante, resultando em uma dispensa de outorga, são realizadas as verificações de disponibilidade hídrica e inclusão no SIGO Lançamento de Efluentes, assim como em processos de outorga para lançamento de efluentes. 

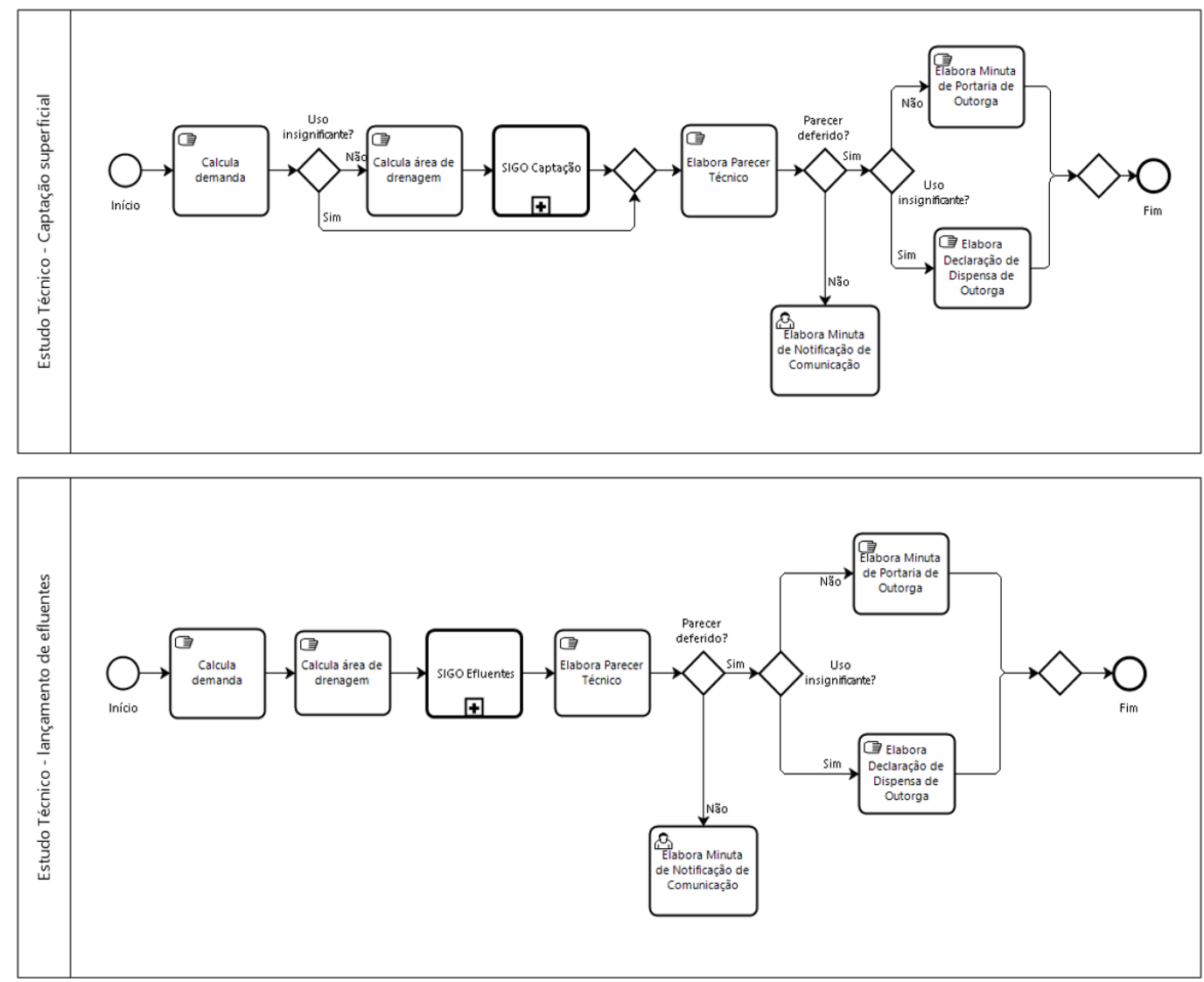

Figura 3: Fluxo "AS IS" do subprocesso Estudo Técnico. Fonte: As autoras.

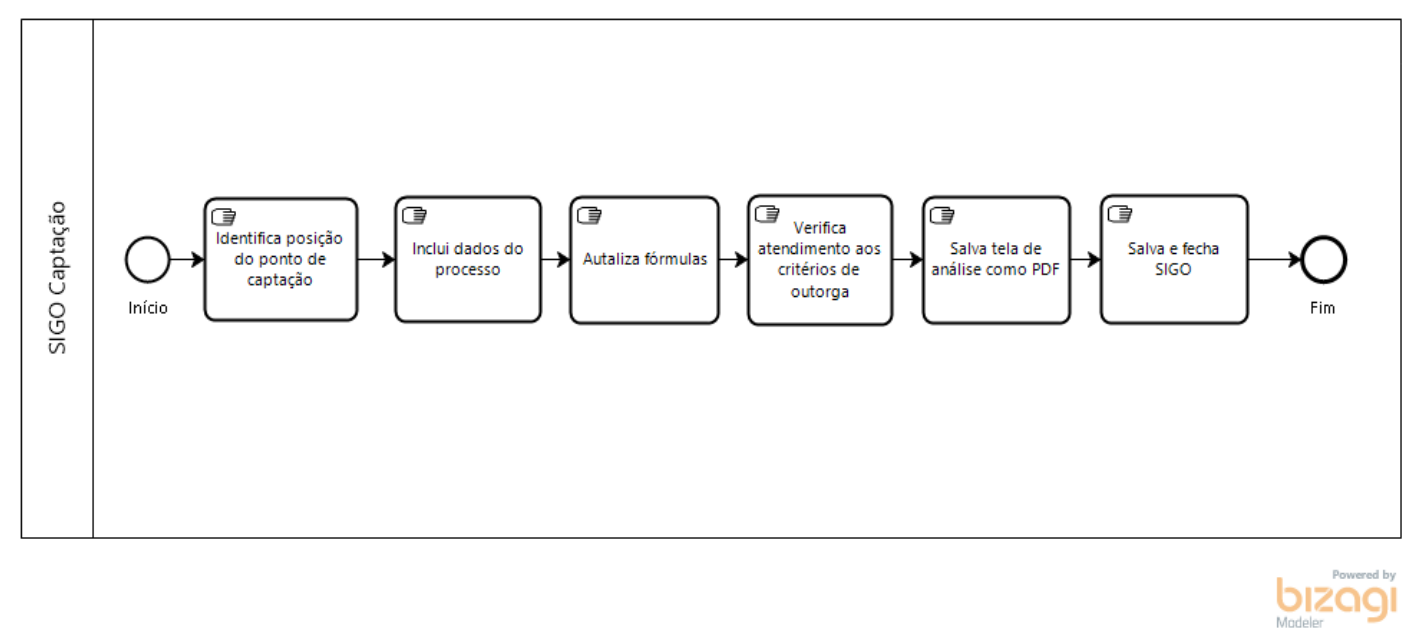

Figura 4: Fluxo "AS IS" do subprocesso SIGO Captação. Fonte: As autoras. 


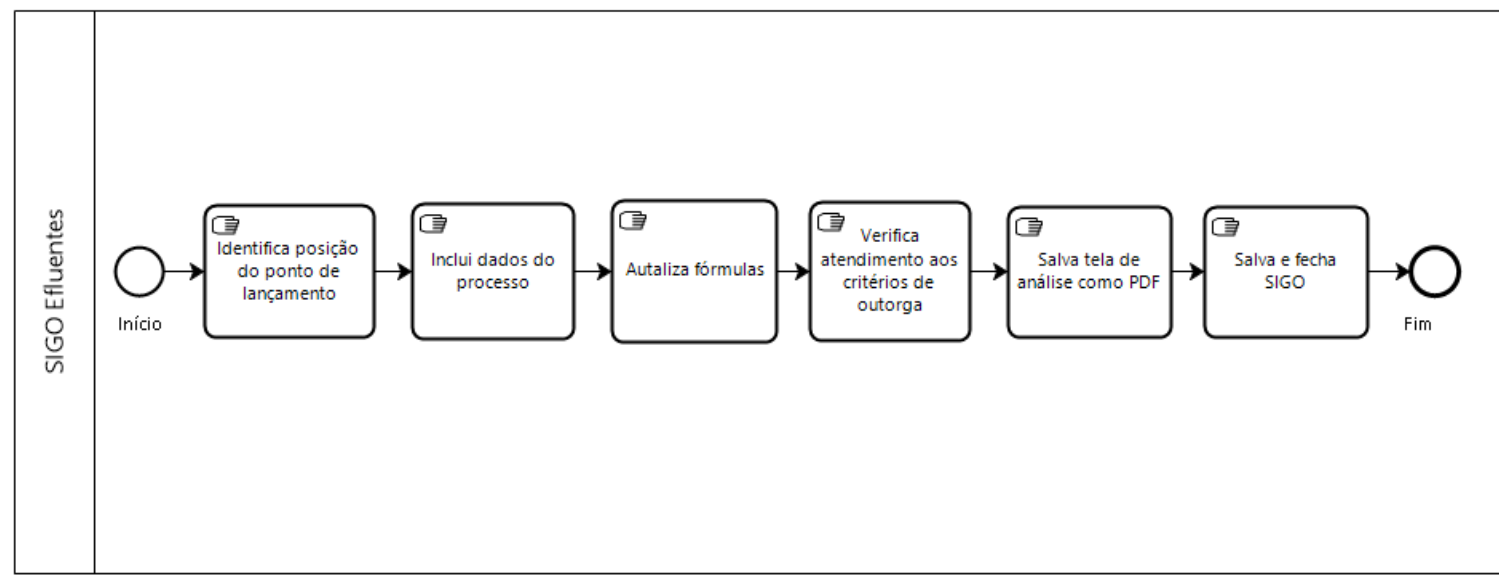

Figura 5: Fluxo "AS IS" do subprocesso SIGO Lançamento. Fonte: As autoras.

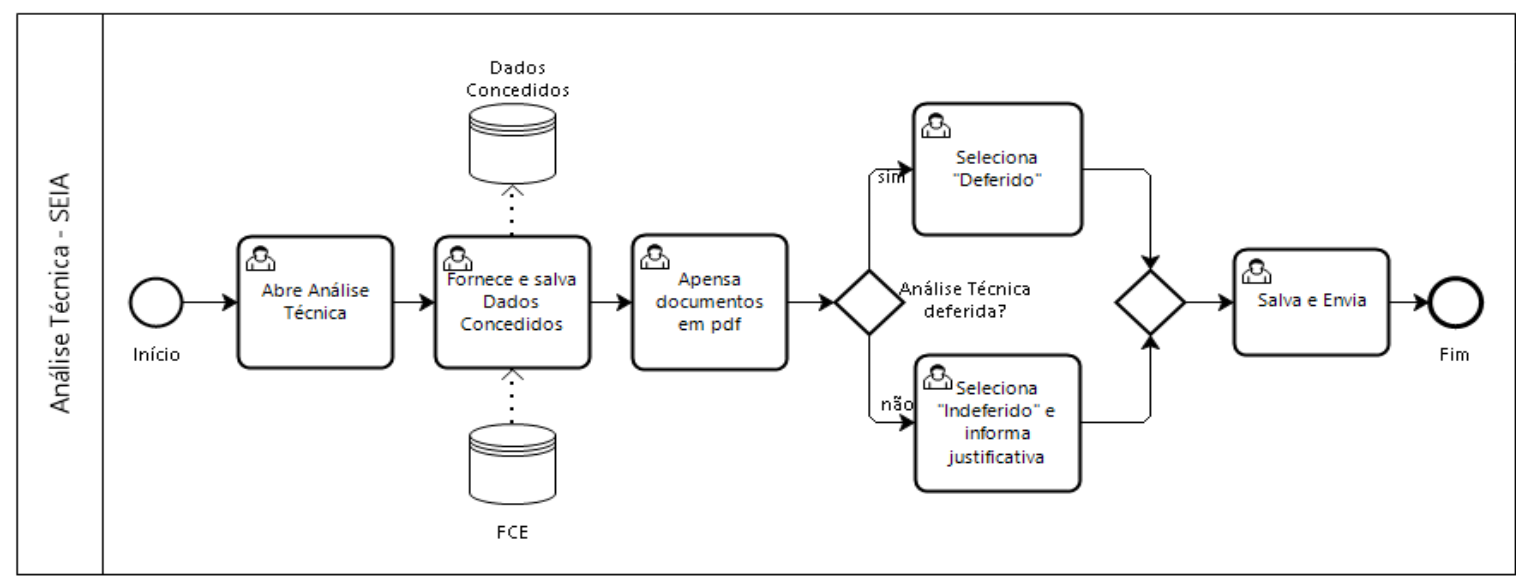

Figura 6: Fluxo "AS IS" do subprocesso Análise Técnica - SEIA. Fonte: As autoras.

\section{Etapa 2 - Análise da situação atual e identificação dos pontos de melhoria}

Conforme apresentado na Figura 2, a Análise Técnica do Processo de Outorga inclui etapas de verificações e envios de notificações para adequações dos documentos enviados, ajustes na demanda para atendimento dos critérios de outorga ou comunicação de arquivamento do processo. Durante a análise da situação atual, verificou-se que $o$ mapeamento poderia ser simplificado para fins de análise e proposição de melhorias, tratando as tarefas de verificações e notificações como exceções ao fluxo do processo. Ou seja, o mapeamento simplificado foi representado considerando um processo onde não é necessário solicitar complementação ou alteração até a finalização da análise.

A Figura 7 apresenta o mapeamento do processo de Análise Técnica de outorga simplificado distinguindo as tarefas que são realizadas utilizando o SEIA ou outros sistemas ou ferramentas. 


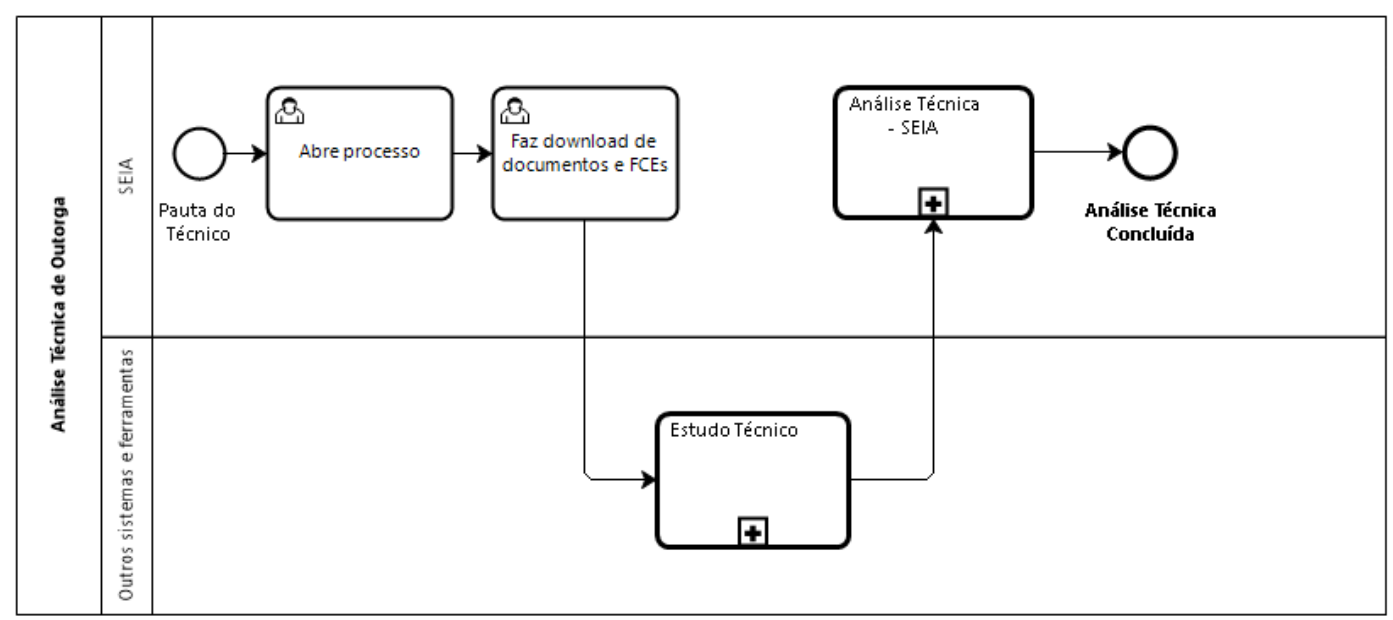

Figura 7: Mapeamento “AS IS" do Processo Análise Técnica de Outorga simplificado.

Fonte: As autoras.

Com o mapeamento simplificado, as tarefas do processo "Análise de Processo de Outorga" e dos seus subprocessos foram detalhadas. O Quadro 2 apresenta o exemplo do detalhamento realizado para o processo "Análise de Processo de Outorga", não incluindo os seus subprocessos.

Com o detalhamento das atividades, foi possível verificar que a maior parte das oportunidades de melhorias apresentadas está relacionada com a possibilidade de automatização da tarefa e incorporação desta no SEIA, diminuindo o tempo de análise, a possibilidade de erro humano e a confiabilidade do processo. Além disso, com a automatização das etapas, é possível diminuir o volume de arquivos armazenados em rede e em máquinas e aumentar a quantidade de dados armazenados em banco de dados, sendo possível transformá-los em informação. Foram também identificadas oportunidades de melhorias no desenvolvimento ou aprimoramento de procedimentos operacionais relacionados à determinação da disponibilidade hídrica para outorga, visto que atualmente as atividades relacionadas são realizadas apenas de acordo com a experiência do técnico analista do órgão gestor.

Quadro 2: Detalhamento do Processo Análise Técnica de Outorga.

\begin{tabular}{|c|c|}
\hline \multicolumn{2}{|c|}{ PROCESSO: ANÁLISE TÉCNICA DE OUTORGA } \\
\hline \multicolumn{2}{|c|}{ TAREFA: Abre Processo } \\
\hline OBJETIVO & Acessar informações do processo \\
\hline \multirow{14}{*}{ ENTRADAS } & 1. Dados fornecidos/gerados na etapa de Requerimento: \\
\hline & - Número do processo \\
\hline & - Nome/Razão Social \\
\hline & $-\mathrm{CPF} / \mathrm{CNPJ}$ \\
\hline & - Data de Formação \\
\hline & - Nome do empreendimento \\
\hline & - Localidade \\
\hline & - E-mail \\
\hline & - Status atual \\
\hline & - Ato(s) e Dado(s) do Processo \\
\hline & - $\mathrm{N}^{\circ}$ do Requerimento \\
\hline & - Documentos de Formação do Processo \\
\hline & - Formulário(s) de Caracterização do Empreendimento (FCE) \\
\hline & 2. Histórico de movimentações do processo \\
\hline
\end{tabular}


Quadro 2. Continuação...

\begin{tabular}{|c|c|}
\hline & 3. Notificações emitidas \\
\hline \multirow{2}{*}{$\begin{array}{l}\text { DESCRIÇÃO DAS } \\
\text { ATIVIDADES }\end{array}$} & Com a tela da Pauta do Técnico aberta, clica no número do processo. \\
\hline & $\begin{array}{c}\text { É aberta a janela "Detalhes do Processo" e visualizada a primeira aba desta janela, } \\
\text { denominada "Atos e Dados Gerais". }\end{array}$ \\
\hline \multirow{2}{*}{ SAÍDAS } & - Abas da janela "Detalhes do Processo" preenchidas com informações do processo. \\
\hline & - Documentos para download. \\
\hline $\begin{array}{l}\text { DOCUMENTOS DE } \\
\text { REFERÊNCIA }\end{array}$ & Manual do SEIA (Instituto do Meio Ambiente e Recursos Hídricos, 2020) \\
\hline $\begin{array}{l}\text { OPORTUNIDADES DE } \\
\text { MELHORIAS }\end{array}$ & $\mathrm{N} / \mathrm{D}$ \\
\hline \multicolumn{2}{|r|}{ TAREFA: Faz download de documentos e FCEs } \\
\hline OBJETIVO & Fazer download dos documentos necessários para análise do processo. \\
\hline \multirow{3}{*}{ ENTRADAS } & 1. Dados fornecidos/gerados na etapa de Requerimento: \\
\hline & - Documentos de Formação do Processo \\
\hline & - Formulário(s) de Caracterização do Empreendimento (FCE) \\
\hline \multirow{3}{*}{$\begin{array}{c}\text { DESCRIÇÃO DAS } \\
\text { ATIVIDADES }\end{array}$} & $\begin{array}{l}\text { Com a janela "Detalhes do Processo" aberta, clica na aba "Docs de Formação" e faz o } \\
\text { download dos documentos: }\end{array}$ \\
\hline & $\begin{array}{l}\text { - No quadro "Documentos de Formação do Processo", documentos que foram } \\
\text { anexados ao processo pelo requerente em formato PDF. }\end{array}$ \\
\hline & $\begin{array}{l}\text { - No quadro "Formulário de Caracterização do Empreendimento - FCE", documento } \\
\text { em formato PDF gerado a partir das informações fornecida no(s) FCE(s) } \\
\text { preenchido(s). }\end{array}$ \\
\hline \multirow{2}{*}{ SAÍDAS } & Documentos de Formação do Processo em formato PDF. \\
\hline & Formulário(s) de Caracterização do Empreendimento (FCE) em formato PDF. \\
\hline $\begin{array}{l}\text { DOCUMENTOS DE } \\
\text { REFERÊNCIA }\end{array}$ & Manual do SEIA (Instituto do Meio Ambiente e Recursos Hídricos, 2020) \\
\hline $\begin{array}{l}\text { OPORTUNIDADES DE } \\
\text { MELHORIAS }\end{array}$ & $\mathrm{N} / \mathrm{D}$ \\
\hline \multicolumn{2}{|r|}{ Subprocesso Estudo Técnico } \\
\hline & Subprocesso Análise Técnica - SEIA \\
\hline
\end{tabular}

Fonte: As autoras.

Etapa 3 - Redesenho de processos e subprocessos resultantes (TO-BE)

A partir do mapeamento AS-IS e seu detalhamento, o processo foi repensado, gerando um novo mapeamento do processo, denominado TO-BE contendo soluções para as oportunidades de melhorias identificadas.

0 modelo proposto teve o objetivo principal de automatizar etapas realizadas fora do SEIA e que são possíveis de serem incorporadas ao mesmo considerando aquelas que têm seus procedimentos bem definidos e que necessitam de dados de entrada que já estão disponíveis em banco de dados existentes ou possíveis de serem criados.

Nesta proposta, não foi distinguida a análise de usos insignificantes dos usos passíveis de outorga. Considerou-se que as análises realizadas para usos insignificantes são realizadas da mesma forma que para os usos outorgados, com objetivo de inserir todas as informações sobre usos no sistema de balanço hídrico, obtendo um conhecimento sobre demandas existentes mais próximo da realidade.

Outra possibilidade seria automatizar a emissão de dispensas de outorga na etapa de requerimento, fazendo com que estes processos não fizessem mais parte do processo de Análise Técnica de Outorga. No entanto, para que os usos insignificantes não passem mais por análise do órgão gestor, é necessário ainda estabelecer critérios de criticidade em bacias, conhecendo melhor a situação atual do comprometimento hídrico destas. Dessa forma, optou-se por continuar realizando as análises, alterando apenas a inclusão das informações de usos dispensados de outorga no balanço hídrico, o que pode subsidiar a decisão futura de automatização da emissão de dispensas de outorga. 
Na Figura 8 é possível observar o mapeamento do modelo proposto para o processo de Análise Técnica de outorga simplificado distinguindo as tarefas que são realizadas utilizando o SEIA daquelas que utilizam outros sistemas ou ferramentas.

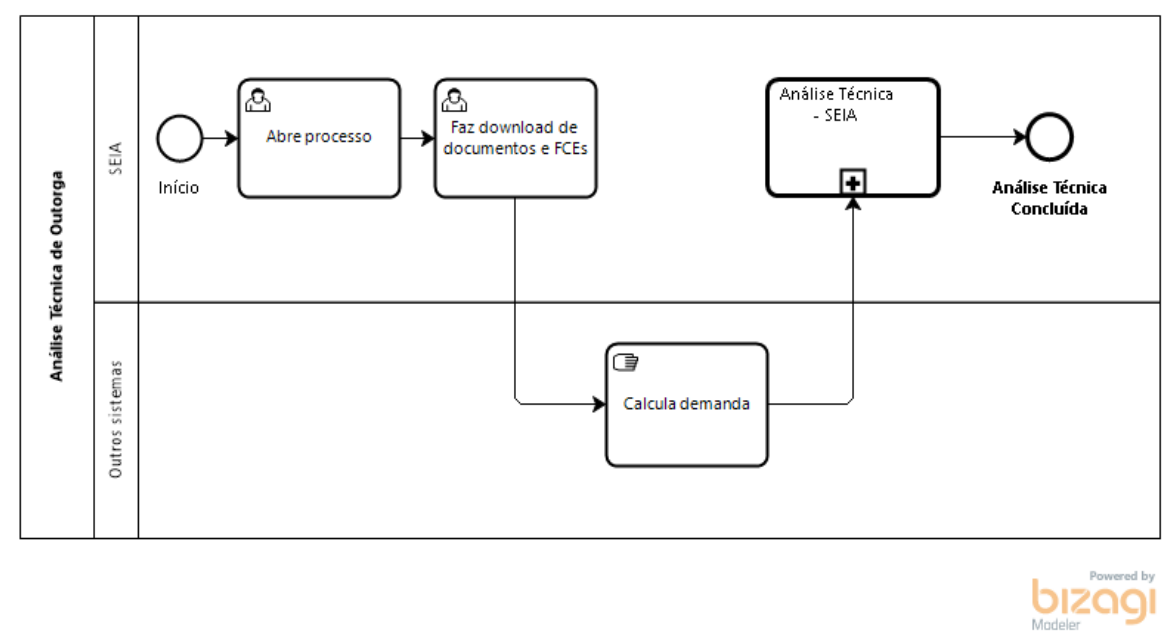

Figura 8: Mapeamento “TO BE” do Processo Análise Técnica de Outorga simplificado. Fonte: As autoras.

Conforme pode ser verificado na Figura 8, as tarefas descritas no subprocesso (AS-IS) Estudo Técnico foram incorporadas ao subprocesso Análise Técnica - SEIA, restando apenas a tarefa "Calcula demanda" para ser realizada fora do SEIA. Apesar de terem sido demonstradas oportunidades de melhorias, com a automatização da tarefa "Calcula demanda", os procedimentos para todas as finalidades de outorga ainda não são bem definidos e não há dados de entrada disponíveis em banco de dados existente para todas as finalidades de outorga. As avaliações de demandas são realizadas de acordo com os projetos dos empreendimentos, que podem ser de diversos tipos, cada um com a sua especificidade. Sendo assim, não é recomendado, nos moldes atuais da análise realizada, automatizar esta etapa. Para isso, é necessário primeiro padronizar a metodologia de análise considerando grupos de finalidades. Dessa forma, para automatização desta etapa, é necessário realizar um trabalho de melhoria de processos específico para esta atividade, de forma a obter insumos necessários para levantar os requisitos da automatização e organizar um banco de dados a ser utilizado.

Na Figura 9 é possível observar o mapeamento proposto para o subprocesso Análise Técnica - SEIA.

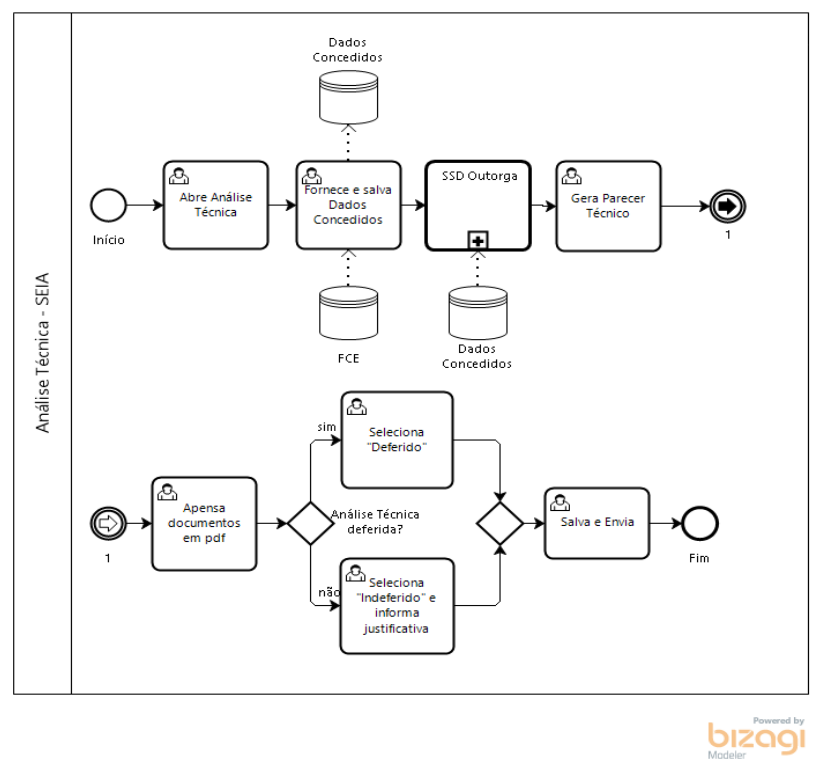

Figura 9: Mapeamento TO-BE do Subprocesso Análise Técnica - SEIA. Fonte: As autoras. 
Durante o primeiro mapeamento TO-BE do processo de Análise Técnica e após a sua finalização, o mesmo foi verificado quanto à coerência, redundância e relevância das etapas apresentadas, tendo como resultado a simplificação dos processos com exclusão das etapas desnecessárias. Além dessas etapas desnecessárias, foi identificada uma etapa incoerente com a atividade do analista técnico, a tarefa de Geração de Minuta de Portaria. Esta tarefa se mostrava importante quando elaborada de forma manual pelo analista, revisada e transformada em documento final pela Diretoria Geral. No entanto, com a possibilidade de automatização desta etapa, o ideal é que a mesma seja realizada no momento da elaboração do documento final, que acontece na última etapa de tramitação do processo de outorga, na Diretoria Geral, não sendo escopo do projeto de melhorias em questão, já que não está incluído no Processo de Análise Técnica. Além disso, existe projeto em desenvolvimento na Secretaria do Meio Ambiente do estado da Bahia (SEMA) para desenvolvimento de Parecer Técnico e de Portaria de Outorga automatizados. Dessa forma, conforme pode ser verificado na Figura 9, a tarefa Elaborar Minuta de Portaria não consta mais como uma etapa do processo de Análise Técnica de outorga.

Comparando-se o mapeamento AS-IS (Figura 6) com o mapeamento TO-BE (Figura 9) deste subprocesso, é possível verificar que o modelo atual, apesar de armazenar as informações de Dados Concedidos, não fazia uso destas. No modelo proposto, as informações de Dados Concedidos armazenadas em banco de dados serão utilizadas para subsidiar o funcionamento do SSD outorga, bem como para outras funcionalidades, como geração de Parecer Técnico e Relatórios Gerenciais. Dessa forma, segue-se a diretriz prevista no projeto, de transformar dados em informações.

A partir da comparação dos mapeamentos AS-IS (Figura 6) e TO-BE (Figura 9) também é possível perceber que a diferença entre os dois foi a adição de um subprocesso (SSD Outorga) e uma tarefa (Gerar Parecer Técnico). No entanto, apesar de terem sido adicionadas informações neste mapeamento, isso significou eliminar o subprocesso Estudo Técnico, seus subprocessos SIGO Captação e SIGO Lançamento e, principalmente, as tarefas manuais envolvidas, que representavam idas e vindas entre sistemas e ferramentas com grande tempo de execução, atividades repetitivas, exaustivas e com alto risco de erro humano.

Existe projeto em desenvolvimento na Secretaria do Meio Ambiente do estado da Bahia (SEMA) para desenvolvimento de Parecer Técnico e de Portaria de Outorga automatizados. Dessa forma, foi apresentado o local sugerido para acionamento da funcionalidade de geração de Parecer Técnico, e foi realizada uma breve descrição proposta para a funcionalidade.

Em se tratando da automatização do Sistema de Suporte à Decisão (SSD) para outorga, foi proposta a criação de um subprocesso a ser acessado por meio da tela do subprocesso Análise Técnica - SEIA. Ou seja, após o fornecimento dos Dados Concedidos, o analista pode acessar o SSD Outorga preenchido com informações obtidas no SEIA e em bancos de dados acessórios e verificar o atendimento aos critérios de outorga. Esta funcionalidade não existe no SEIA, e por isso, foi realizado o maior detalhamento das tarefas para este sistema, apresentando tabelas resumindo o processamento do sistema para o preenchimento de cada campo.

A Figura 10 apresenta um exemplo da janela de "Análise Técnica" aberta para um processo com solicitação de outorga para captação superficial à fio d'água e lançamento de efluentes.

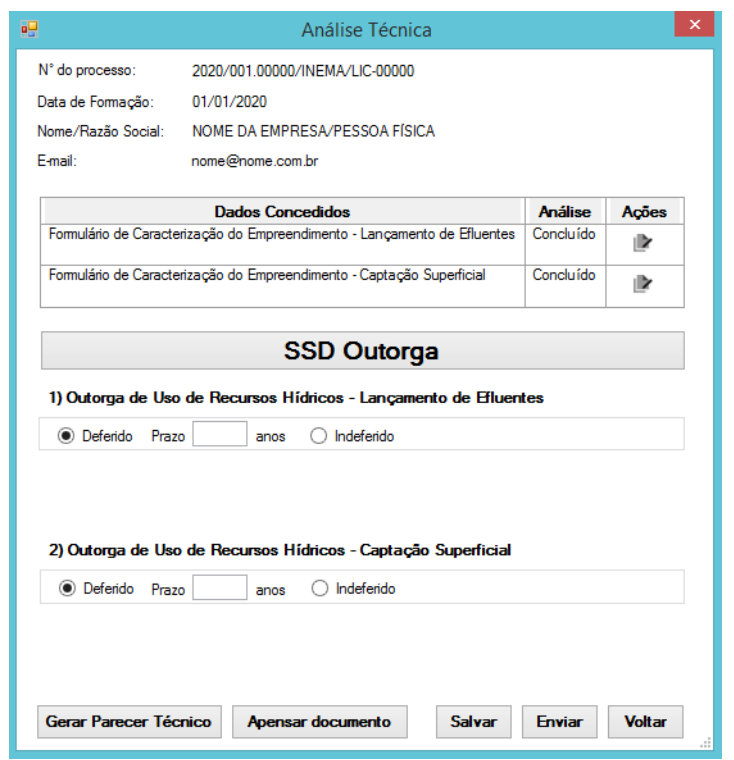

Figura 10: Janela de Análise Técnica (captação superficial à fio d'água e lançamento de efluentes). Fonte: As Autoras 
A proposta inicial do SSD para outorga de corpos hídricos superficiais foi verificada durante o mapeamento do processo, construção do protótipo das telas do SSD para outorga, reuniões com equipes do órgão gestor e apresentação para um grupo focal. Durante a construção dos protótipos das telas do SSD para outorga, foram identificados os seguintes itens que necessitavam de verificações. Alguns destes itens foram resolvidos por meio de questionamentos feitos em reuniões com a equipe da COTIC do Inema e a equipe da SIDA da SEMA e estas reuniões foram registradas por meio de Memórias de Reunião. Além disso, forma feitas consultas à revisão bibliográfica sobre os SSDs para outorga. A seguir serão descritas as verificações realizadas e as resoluções apresentadas.

Na reunião com a COTIC verificou-se ser possível atribuir fórmulas diferentes de cálculo de Q90 bem como os parâmetros necessários para o cálculo aos trechos de corpos hídricos por meio do banco de dados de trecho, não sendo necessário ser informado pelo técnico. Nas reuniões realizadas com a COTIC e com a SEMA verificou-se que é possível gerar o shape de área de drenagem para download, bem como foi recomendado que o técnico realize a alteração da área de drenagem no próprio sistema, diminuindo o risco de ocorrer erro humano na inserção manual da informação no SSD. Além disso, a equipe da SEMA chamou a atenção para o fato de que o Geobahia não tem versões diferentes para usuários internos e externos ao órgão gestor atualmente, dessa forma, não é recomendado utilizar o mesmo no SSD, podendo ser utilizado apenas para gerar informações para os usuários externos. Recorreu-se à revisão bibliográfica sobre os SSDs para outorga e verificou-se que os sistemas SIRIEMA (Mato Grosso do Sul, 2015) e Web-Outorga (Secretaria de Estado de Meio Ambiente e Desenvolvimento Sustentável, 2019) utilizam o recurso de um SIG na interface Web, adotando-se esta ferramenta para a proposta de SSD para outorga.

Com relação ao lançamento em rios intermitentes ou efêmeros, de acordo Art. 15 da Portaria Inema ${ }^{\circ}$ 17.280 de 2018, para estes lançamentos não é realizada a análise de disponibilidade hídrica para fins de diluição. Mesmo assim, é recomendado manter os cálculos de Índices de Comprometimento Qualitativo, para que seja possível visualizar o comprometimento do corpo hídrico com a autorização dos lançamentos de efluentes. Para as exceções nos cálculos de vazão de diluição de efluentes, quando há adoção de metas progressivas e/ou concentração observada de DBO, previu-se a opção de selecionar o botão "Alterar parâmetros de análise" para informar valores diferentes para os parâmetros "concentração permitida de DBO" e "Concentração permitida de Coliformes Termotolerantes".

Também foi questionado às equipes da COTIC do Inema e da SIDA da SEMA se é possível definir status para o uso avaliado, sendo que as duas equipes informaram ser possível criar estes status. Dessa forma, os status foram definidos para serem descritos no mapeamento do processo.

As equipes da COTIC do INEMA e da SIDA da SEMA foram questionadas quanto à adequação do produto final deste trabalho para utilização por uma equipe de desenvolvimento de sistemas para orientação no desenvolvimento do SSD proposto com melhorias no processo de análise técnica de outorga. As duas equipes sinalizaram de forma positiva quanto à adequação do material elaborado, sendo que a equipe da COTIC sugeriu que os documentos citados no mapeamento, como modelos de FCEs, Procedimentos e Normas fossem anexados ao trabalho. Como os documentos citados foram referenciados no trabalho, decidiu-se não incluí-los como anexos.

Após realizados os ajustes mencionados, foi feita reunião com o grupo focal para verificar a aceitação do SSD para outorga proposto e coletar contribuições. A reunião contou com 15 (quinze participantes) e foi registrada em Memória de Reunião. Os presentes fizeram comentários positivos elogiando e parabenizando o trabalho e tiveram dúvidas, principalmente sobre possíveis funcionalidades do sistema, de como se daria a transição dos SIGOs para o SSD proposto e com relação ao planejamento e ao prazo de implantação do sistema. Além disso, foram extraídas contribuições para a proposta, como incluir mecanismos de rastreabilidade para as alterações realizadas e a possibilidade de consultar solicitações de outorgas em análise ou formadas próximas à solicitação avaliada, para verificar possíveis impactos. Ao final, foi aplicado um questionário para os participantes e 11(onze) destes responderam o primeiro item do questionário e 5 (cinco) deles responderam o segundo item. Com base nas respostas apresentadas, ilustradas por meio da Figura 11, é possível afirmar que o sistema teve uma boa aceitação pelo grupo focal, na medida em que as médias das notas apresentadas indicam que o grupo concordou em um grau elevado com as afirmações que indicavam possíveis vantagens na utilização do sistema e discordou das afirmações que apresentavam possíveis desvantagens na utilização do sistema. Além disso, conforme apresentado na Figura 12, nenhum dos presentes identificou necessidade de complementar ou alterar a proposta, sendo que um deles pontuou 
que: "A necessidade de complementação deve ser avaliada melhor quando forem levantados requisitos e regras de negócio."

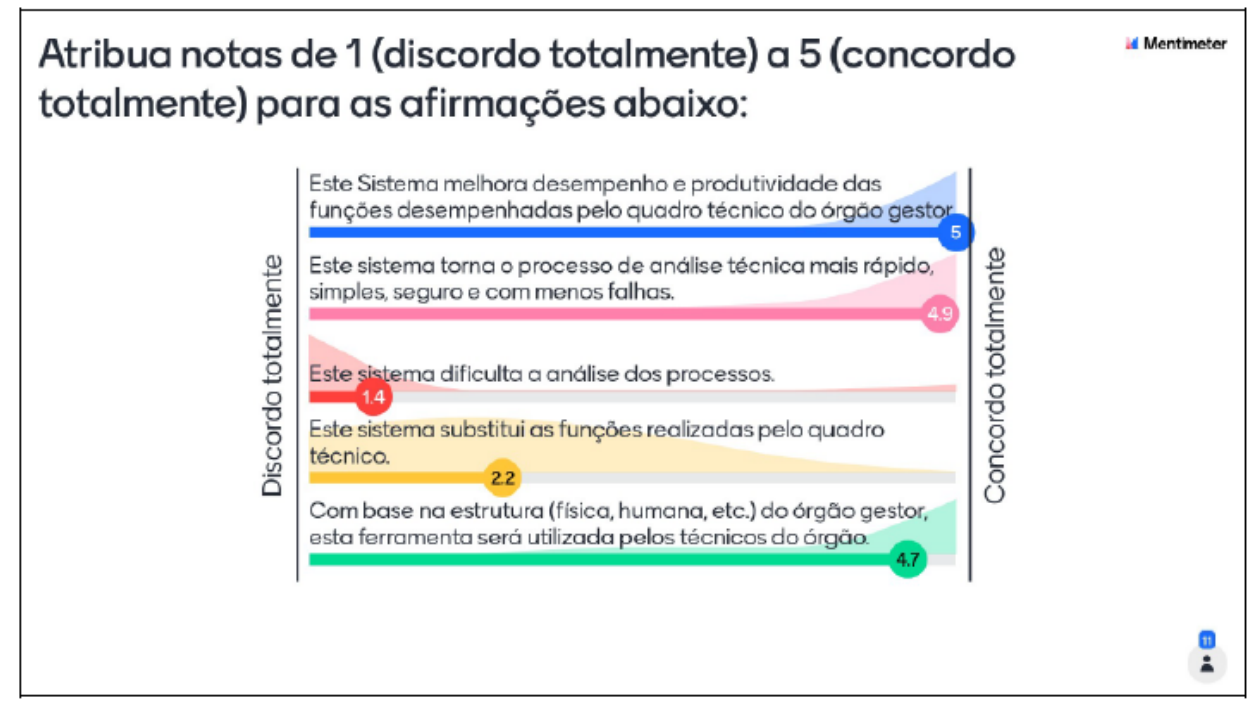

Figura 11: Respostas ao primeiro item do questionário. Fonte: As autoras.

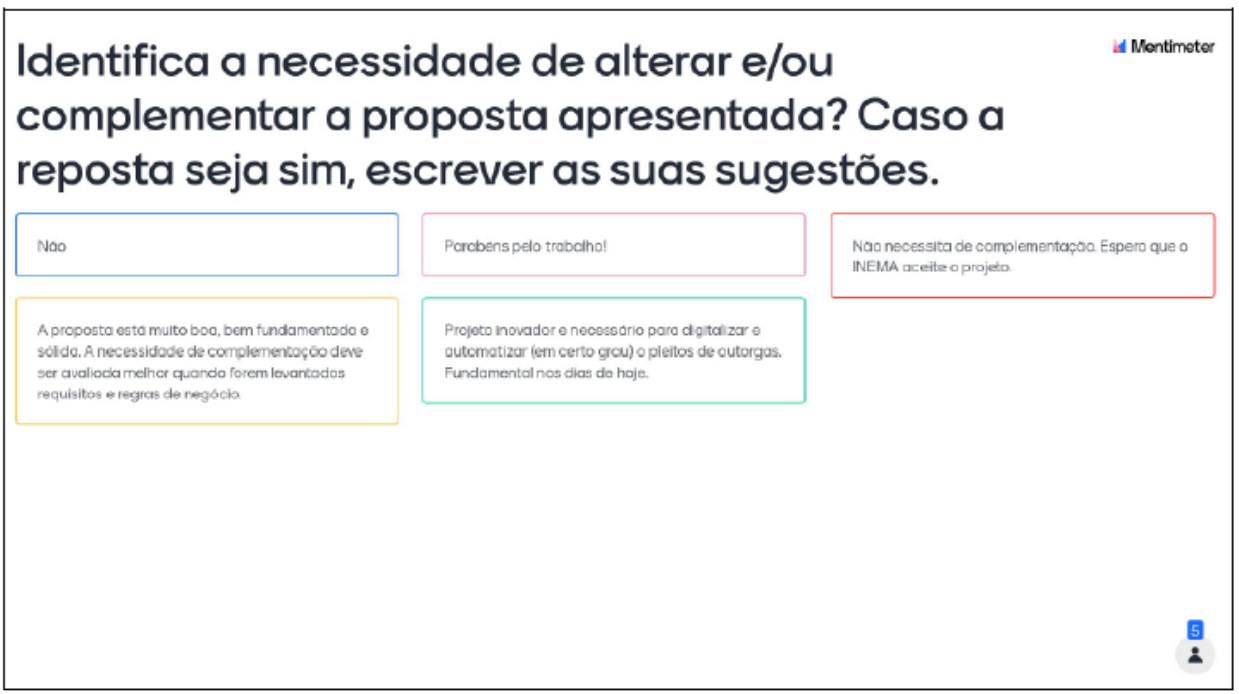

Figura 12: Respostas ao segundo item do questionário.

Fonte: As autoras.

Para a proposição da atualização do SSD para outorga, transformando dois sistemas existentes, externos ao SEIA, em um único sistema acessado por meio do SEIA, inicialmente, foi utilizado como subsídio o SCBH proposto por Collischonn (2014) em sua versão PHP, por considerarem a integração quali-quantitativa em suas análises e ter maior aproximação com os sistemas em funcionamento nos SIGOs. Além disso, considerouse a maior disponibilidade de informações sobre o sistema, a experiência anterior de integração qualiquantitativa utilizando o SCBH para dados de uma bacia do estado da Bahia realizada por Paulo e Silva (2016) e o trabalho finalizado de ottocodificação realizado para a rede hidrográfica deste estado.

Conforme descrito por Collischonn (2014) para consulta do ponto de captação e/ou lançamento avaliado a partir das coordenadas, o sistema deve conter uma camada de informação com um raster da divisão das ottobacias relacionadas com as coordenadas do retângulo envolvente. Assim, partindo das coordenadas do ponto, o sistema converte-as para a linha/coluna da matriz do raster, relacionando com o código do trecho correspondente. Com este código, é possível acessar o banco de dados dos trechos de corpos hídricos e prosseguir com a análise.

Além disso, para captações situadas em reservatórios, pode ser feita uma adaptação ao raster com a sobreposição do shape da área máxima alagada do reservatório sobre a delimitação da hidrografia ottocodificada para que seja possivel identificar os trechos que estão sob influência do barramento (COLLISCHONN, 2014). 
Conforme pode ser verificado na Figura 11, o SSD Outorga foi mapeado considerando que o balanço hídrico entre disponibilidade e demandas pode ser realizado para dois sistemas diferentes: corpos hídricos naturais sem alterações e lagos formados com as construções de barramentos. Dessa forma, foram criadas duas abas distintas no SSD Outorga, a aba Balanço Hídrico à fio d'água e a aba Balanço Hídrico em barramento, esta para apoiar a análise de solicitações de outorga de captação superficial em barragens de regularização e aquela para as análises de captação superficial a fio d'água. Estas abas são habilitadas de acordo com as solicitações (ou atos) cadastradas no processo.

Além das abas distintas para balanço hídrico a fio d'água e em barramento, foram propostas outras inovações com relação ao SCBH de Collishconn (2014), sendo elas:

a) Proposta de utilização de um SIG na interface Web, adotando-se esta ferramenta para a proposta de SSD para outorga, como utilizado pelos sistemas SIRIEMA (Mato Grosso Do Sul, 2015) e Web-Outorga (Secretaria de Estado de Meio Ambiente e Desenvolvimento Sustentável, 2019).

b) Para as exceções nos cálculos de vazão de diluição de efluentes com necessidade de informar parâmetros para cálculo da vazão de diluição diferentes dos que estão cadastrados nos bancos de dados, mencionadas na sexta e na sétima verificação, previu-se a opção de selecionar o botão "Alterar parâmetros de análise" para informar valores diferentes para os parâmetros "concentração permitida de DBO" e "Concentração permitida de Coliformes Termotolerantes".

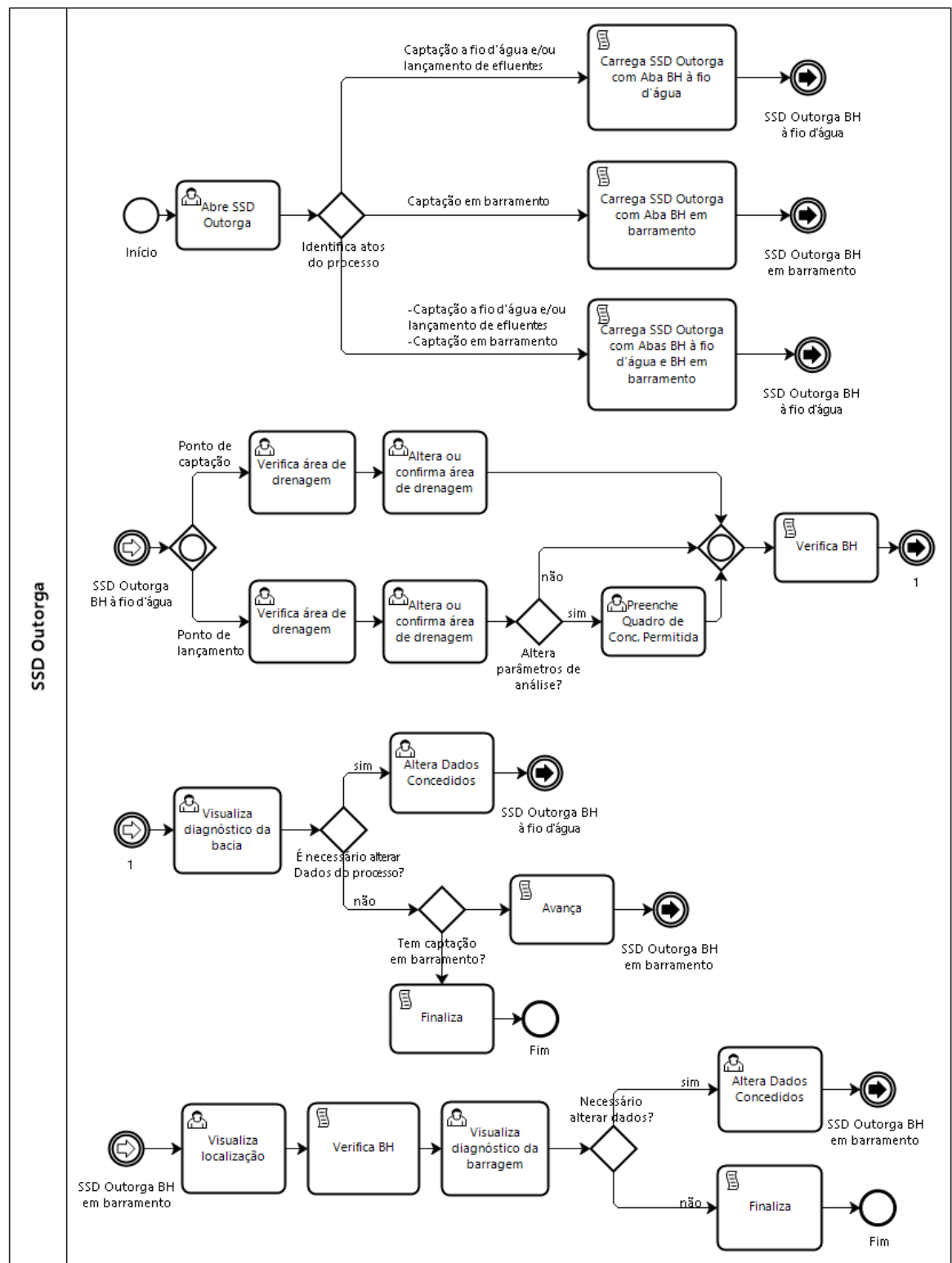

Figura 13: Mapeamento TO-BE do Subprocesso Análise Técnica - SEIA - Subprocesso SSD Outorga. Fonte: As autoras. 
A aba Balanço Hídrico a fio d'água é habilitada com os dados do ponto de captação e os dados do ponto de lançamento. Caso tenha sido solicitada apenas captação, o campo preparado para conter dados do ponto de lançamento não é visualizado, ocorrendo o mesmo para o campo de ponto de captação, quando é solicitado apenas o lançamento de efluentes.

Caso seja solicitado mais um ponto de captação ou lançamento, deverão ser informadas as características para cada ponto, conforme indicado no Manual do SEIA (Instituto do Meio Ambiente e Recursos Hídricos, 2020) e a aba do SSD deverá ser carregada e verificada para todos os pontos.

A maior parte das informações destes campos é preenchida com informações do banco de dados ou de cálculos realizados pelo sistema, salvo o campo de "Alterar parâmetros de análise" para o ponto de lançamento de efluentes, caso seja habilitado, cujo preenchimento é realizado pelo analista técnico. A Figura 12 apresenta o protótipo da janela do SSD Outorga relacionada à um processo com solicitação de captação superficial à fio d'água e lançamento de efluentes com a opção "sim" selecionada para "Alterar parâmetros de análise" mostrando os campos habilitados a serem preenchidos pelo técnico analista.

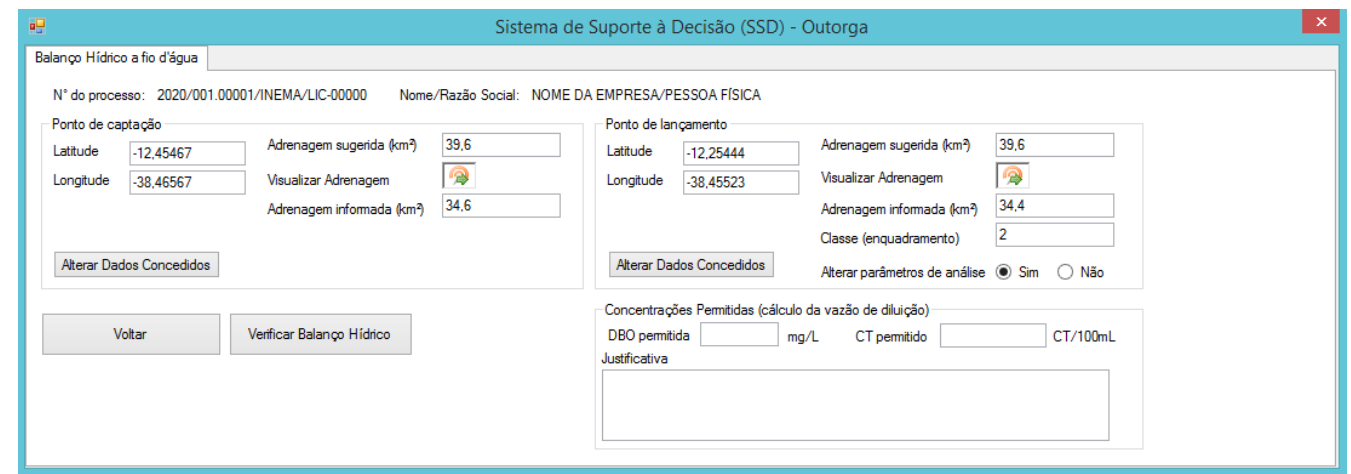

Figura 14: Janela do SSD Outorga com a opção de Alterar parâmetros de análise com a seleção em "sim". Fonte: As Autoras.

Para a determinação da disponibilidade hídrica, recomendou-se a preparação do banco de dados de trechos com a possibilidade de atribuir equações de regionalização distintas, a depender do que tenha sido determinado para o corpo hídrico em análise, seja por meio de proposta oriunda de Planos de Bacias, procedimentos do órgão gestor ou um estudo prévio de atualização da disponibilidade hídrica. Um exemplo é o estudo contratado pela SEMA, descrito em Bahia (2016), para sistematização, diagnóstico e consistência dos dados hidrológicos utilizados para definir a disponibilidade hídrica para fins de outorga no estado da Bahia. A Figura 13 apresenta o protótipo da janela do "SSD Outorga" relacionada à um processo com solicitação de captação superficial à fio d'água e lançamento de efluentes.

A área de drenagem calculada automaticamente utilizando a ottocodificação pressupõe o ponto de análise calculada no nó de saída do trecho avaliado, sendo possível majorar muito a disponibilidade hídrica do ponto analisado. Dessa forma, para obter maior detalhamento no cálculo da vazão de referência para trechos em que o ponto avaliado se encontra distante do ponto considerado para o cálculo da área de drenagem, previu-se a edição, pelo analista, da área de drenagem proposta pelo sistema em um SIG Web. A Figura 14 exemplifica como a exibição no SIG Web pode ser feita, conforme atributos mencionados acima.

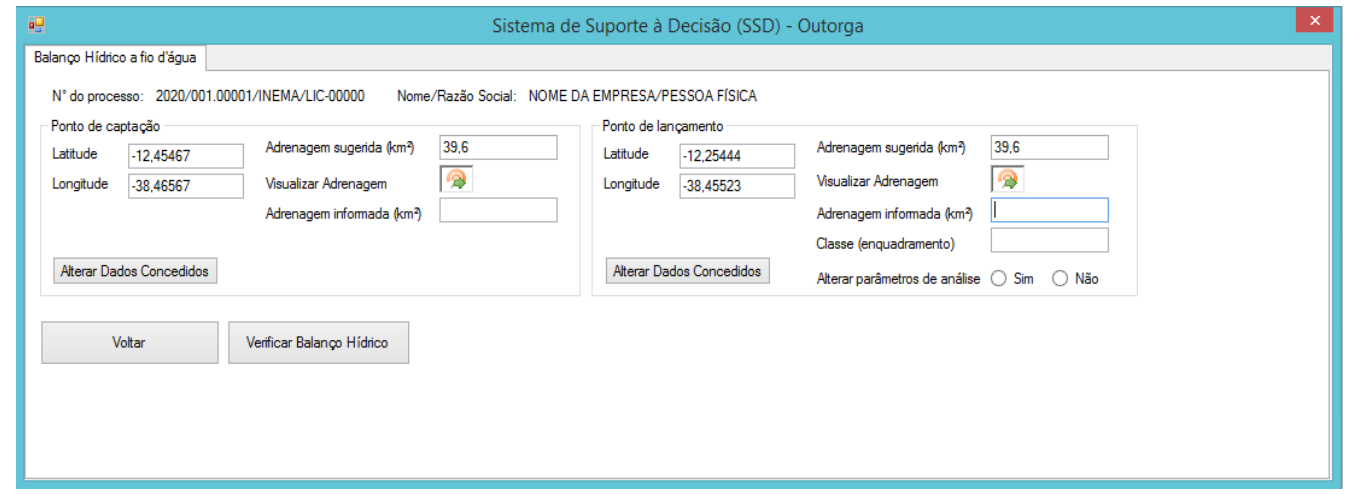

Figura 15: Janela do SSD Outorga com aba BH à fio d'água (captação à fio d'água e lançamento de efluentes). Fonte: As Autoras. 


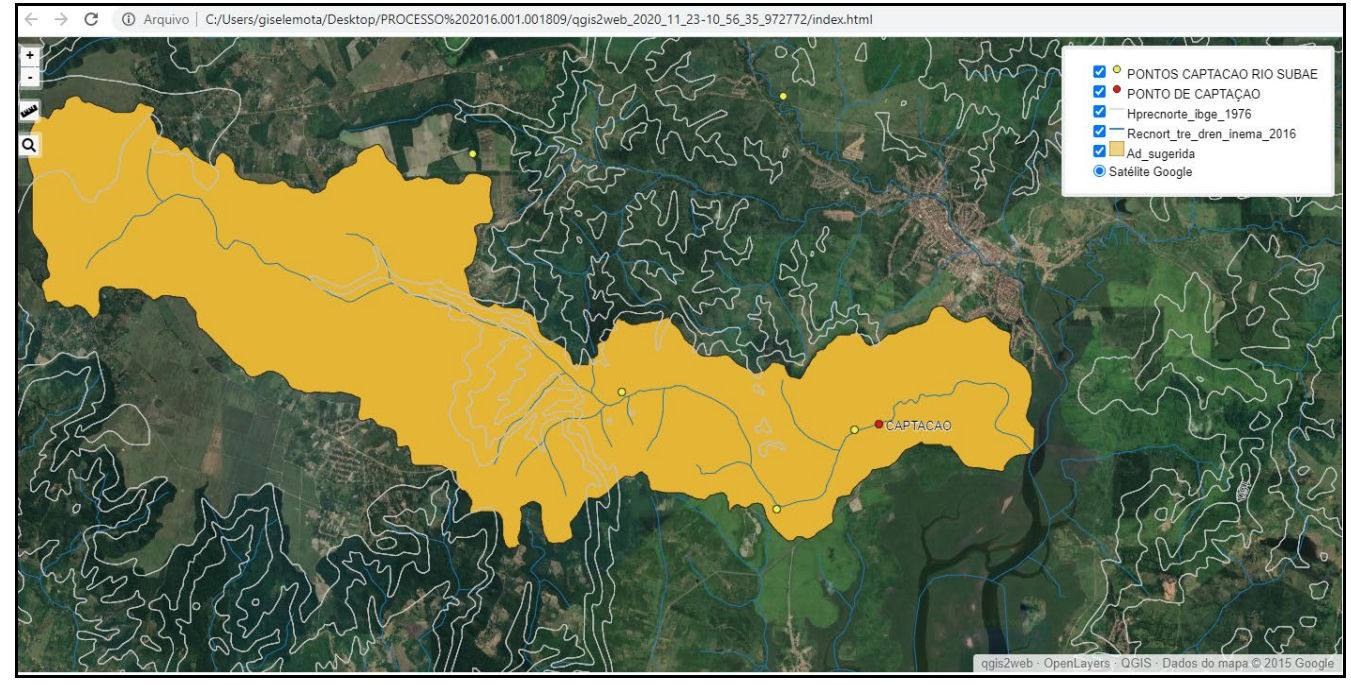

Figura 16: Exemplo de visualização da área de drenagem em um SIG Web (solicitação de captação superficial). Fonte: As Autoras.

Os quadros com informações de comprometimento quantitativo e qualitativo e o resumo dos resultados são mostrados se as informações de captação e/ou lançamento estiverem completas quando o usuário aciona o botão "Verificar balanço hídrico". O sistema realiza os cálculos seguindo a mesma metodologia do SCBH descrito por Collischon (2014) e apresenta os resultados dos índices calculados, destacando-os no caso de descumprimento dos critérios de outorga, previstos na codificação do sistema. Além disso, é gerada a informação sobre a existência ou não de uso impactado à jusante com a adição do novo usuário. É possível visualizar as telas do protótipo elaborado para os campos contidos nos quadros: "Comprometimento Quantitativo", "Comprometimento Qualitativo" e "Resumo" preenchidos, por meio da Figura 15 (atendendo os critérios de outorga) e da Figura 16 (não atendendo os critérios de outorga).

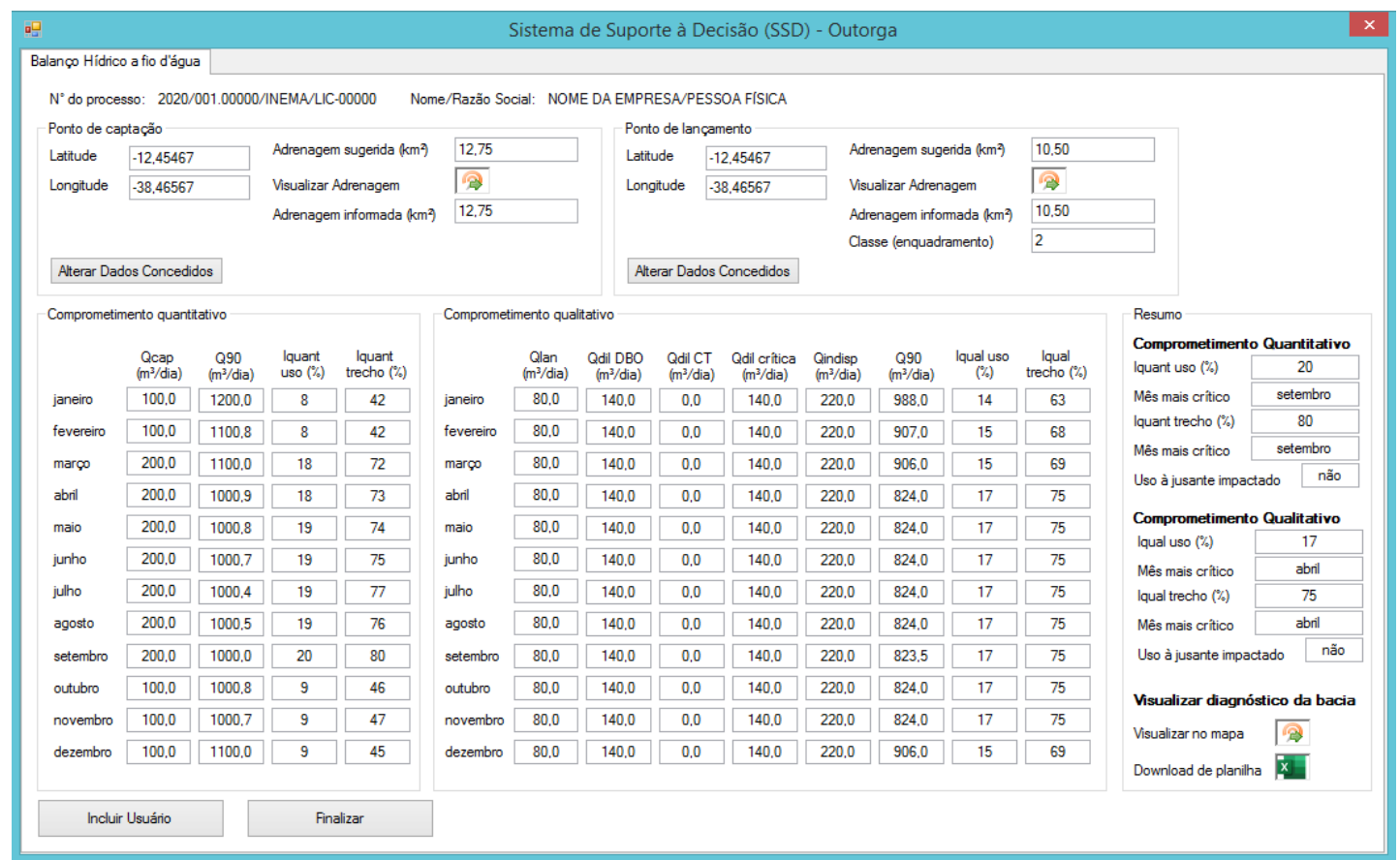

Figura 17: Janela do SSD Outorga aba BH a fio d'água após executar a tarefa "Verificar Balanço Hídrico" (critérios de outorga atendidos). Fonte: As Autoras. 


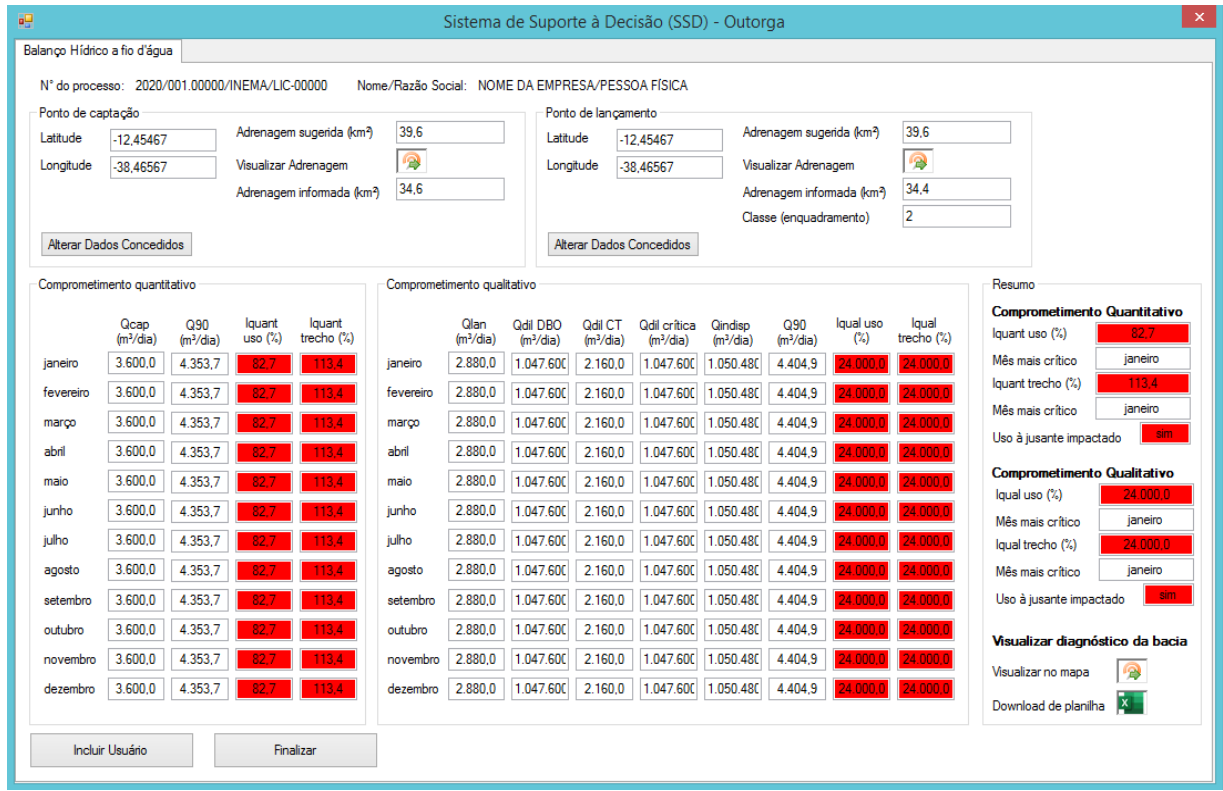

Figura 18: Janela do SSD Outorga aba BH a fio d'água após executar a tarefa "Verificar Balanço Hídrico" (critérios de outorga não atendidos). Fonte: As Autoras.

Nesse momento, é possível verificar o comprometimento da bacia no item "Visualizar diagnóstico da bacia" por meio dos ícones "Visualizar no mapa" e "Download de planilha". Por meio do primeiro ícone, se tem acesso à um SIG Web carregado com o mapa do estado da Bahia e o zoom para o local analisado. São carregados dois shapes disponíveis para habilitar e desabilitar na aba de camadas do mapa demonstrando os resultados para os índices de comprometimento quantitativo e qualitativo associados a cada trecho da hidrografia. Já o segundo ícone dá acesso aos resultados de cálculo para todos os usuários da bacia avaliada, da nascente até a foz.

Ao clicar no ícone "Visualizar mapa", o sistema gera dois shapes: a) comp_quant.shp: contendo as informações dos trechos de corpos hídricos e um valor de Iquanttrecho associado a cada trecho; e b) comp_qual.shp: contendo as informações dos trechos de corpos hídricos e um valor de Iqualtrecho associado a cada trecho. 0 sistema deve abrir tela de um SIG Web com o mapa do estado da Bahia e o zoom para o local analisado. São carregados os dois shapes (comp_quant.shp e comp_qual.shp) disponíveis para habilitar e desabilitar na aba de camadas do mapa. Além disso, devem ser atribuídos critérios de visualização em escala de cores para identificar trechos com maior criticidade de comprometimento, tanto para o Iquant techo quanto para o Iqual trecho, conforme exemplo apresentado na Figura 19.

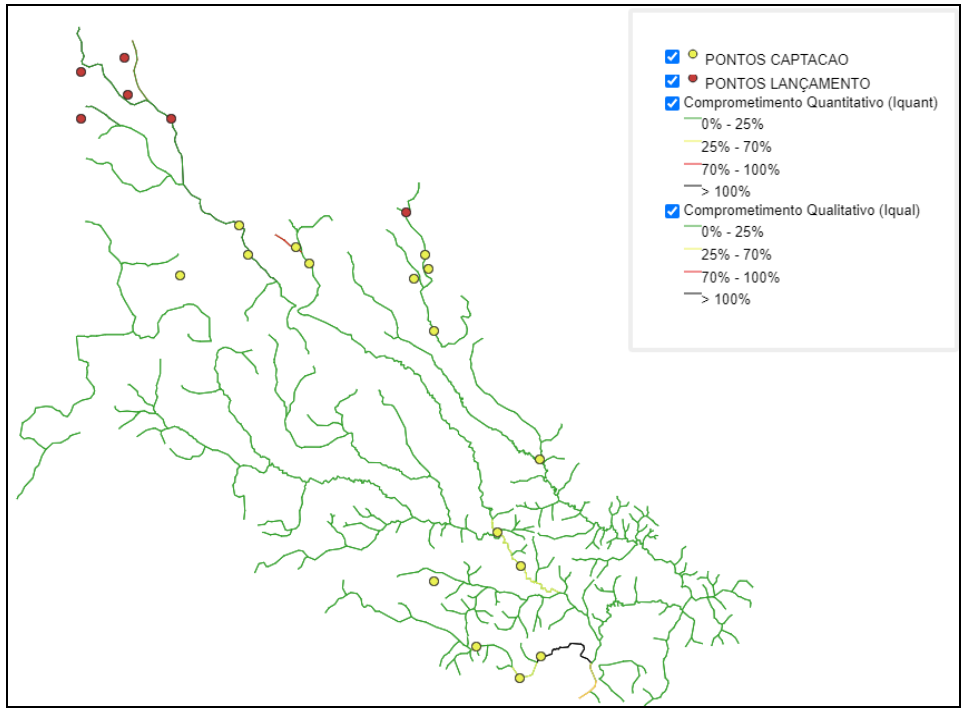

Figura 19: Exemplo de resultado de diagnóstico com visualização em um SIG Web. Fonte: As Autoras. 
Após análise das informações apresentadas pelo SSD, o técnico é capaz de tomar a decisão sobre o deferimento ou não da solicitação de outorga. Caso seja necessário alterar os dados de captação e/ou lançamento, é possível acessar a função de "Fornecer Dados Concedidos" por meio do ícone "Alterar Dados Concedidos". Caso não seja necessário alterar os dados concedidos, o processo é finalizado ou, caso também esteja sendo analisada a captação em barramento, o analista deve acessas a aba "Balanço hídrico em barramento" e iniciar a análise.

A análise do balanço hídrico em um sistema de lago de barragens se diferencia da análise a fio d'água pela disponibilidade hídrica a ser utilizada como referência, que, neste caso, é a vazão regularizada com 90\% (noventa por cento) de permanência (Q90reg). Este dado é obtido por meio da identificação da barragem, que é cadastrada previamente no sistema por meio da solicitação de outorga para construção de barramento, onde são registrados os dados de Identificação da Barragem e a Q90reg. Nesta aba também é possível acessar os Dados Concedidos referentes à captação superficial para realizar alterações.

\section{Orientações para preparação e implementação do SSD para outorga}

A implantação do SSD para outorga foi dividida em 4 (quatro) fases para fins de orientação e entendimento sobre os requisitos necessários para funcionamento do sistema.

a) FASE 1: Desenvolvimento de Sistema de Suporte à Decisão para Outorga

Partindo do mapeamento TO-BE, a equipe de desenvolvimento poderá se preparar para realizar as reuniões de levantamento de requisitos e regras de negócio junto à equipe do Núcleo de Outorga da Diretoria de Regulação do Inema.

Com as reuniões realizadas com a equipe do Núcleo de Outorga da Diretoria de Regulação espera-se que sejam solucionadas dúvidas da equipe de desenvolvimento que podem surgir mesmo com a consulta ao mapeamento do processo, bem como detalhar melhor o sistema, de acordo com as necessidades do mesmo.

A partir do levantamento de requisitos e definição das regras de negócio, o sistema poderá entrar em desenvolvimento pela equipe.

b) FASE 2: Preparação de banco de dados para subsidiar o funcionamento do sistema

Para operacionalização do sistema proposto foram previstos quatro Bancos de Dados (BD) a serem acessados e atualizados, sendo eles: a) Dados Concedidos, b) Trechos, c) Usuários e d) Reservatórios.

Inicialmente estes Bancos de Dados deverão ser preparados para serem carregados no SEIA e serão atualizados a cada finalização de processo de análise técnica de outorga.

Para que o sistema possa funcionar adequadamente, é necessário que os quatro bancos de dados previstos no Item 6.1.1.3 sejam preparados e inseridos no SEIA. De acordo com recomendação feita pela equipe da SIDA da SEMA, os bancos de dados necessários para funcionamento do SSD devem ser, preferencialmente, bancos de dados do SEIA, para que não sejam criadas dependências de outros sistemas, bem como para que estes dados possam ser utilizados em outras funcionalidades e módulos do SEIA.

c) FASE 3: Desenvolvimento de Funcionalidade de Geração Relatórios Gerenciais

A funcionalidade de geração de Relatórios Gerenciais no SEIA para apresentar dados de usos da água tem o objetivo de melhorar a capacidade de gerenciamento pela equipe do órgão gestor, na medida em que poderá atuar de forma planejada a partir de maior conhecimento sobre os usos dos recursos hídricos. Estes relatórios poderão gerar informações para a equipe técnica atuante na análise de pleitos de outorga, como também para equipes atuantes na operacionalização dos outros instrumentos da Política de Recursos Hídricos no estado, colaborando com a melhoria da integração entre os instrumentos. Atualmente existe a funcionalidade de Relatórios no SEIA para gerar informações de quantitativos de processos, no entanto não apresentam detalhamento quanto aos usos realizados, nem informações de comprometimento hídrico.

Com as informações dos bancos de dados elaborados para funcionamento do SSD e com o próprio funcionamento do sistema, haverá informações suficientes disponíveis para gerar os seguintes relatórios:

- USUÁRIOS DE RECURSOS HÍDRICOS COM OUTORGA VÁLIDA POR: a) RPGA; b) bacia hidrográfica; c) município; d) tipologia de uso dos recursos hídricos. 
- USUÁRIOS DE RECURSOS HÍDRICOS COM OUTORGA VENCIDA POR: a) RPGA; b) bacia hidrográfica; c) município; d) tipologia de uso dos recursos hídricos.

- IINDICES DE COMPROMETIMENTO HÍDRICO POR: a) RPGA; b) bacia hidrográfica; c) município.

d) FASE 4: Desenvolvimento de Funcionalidade de Consulta Pública de usuários de recursos hídricos e de índices de comprometimento hídrico por meio do Geobahia.

A funcionalidade de Consulta Pública de usuários de recursos hídricos e de índices de comprometimento hídrico por meio do Geobahia tem o objetivo facilitar a disponibilização de informações pelo órgão gestor, e, consequentemente, melhorar a sua transparência.

Com as informações dos bancos de dados elaborados para funcionamento do SSD e com o próprio funcionamento do sistema, haverá informações suficientes disponíveis para alimentar o Geobahia com os shapes de usuários (a partir do banco de dados de usuários apenas para aqueles que tenham o status "OUTORGA VÁLIDA"), bem como o shape de índices de comprometimento hídrico (a partir do banco de dados de trechos), sendo os índices calculados apenas considerando os usuários que tenham o status "OUTORGA VÁLIDA".

A visualização das informações pelos usuários externos deverá ser feita das seguintes maneiras:

- Geobahia carregado com a possibilidade de habilitar, além das camadas existentes atualmente, a camada de usuários outorgados, a camada de comprometimento quantitativo e a camada de comprometimento qualitativo. As camadas de índices de comprometimento deverão ser apresentadas em cores categorizadas de acordo com os valores de índices de comprometimento, conforme foi exemplificado (Figura 20).

- Opção de realizar o download de uma planilha eletrônica com os dados de usuários de recursos hídricos contendo os seguintes campos: a) $\mathrm{n}^{\circ}$ do processo; b) $\mathrm{n}^{\circ}$ da portaria de outorga; c) validade da portaria de outorga; d) coordenadas geográficas do ponto de interferência; e) vazão (m³/dia); f) nome/razão social; g) município; h) RPGA; i) bacia hidrográfica; j) manancial; k)tipologia do uso.

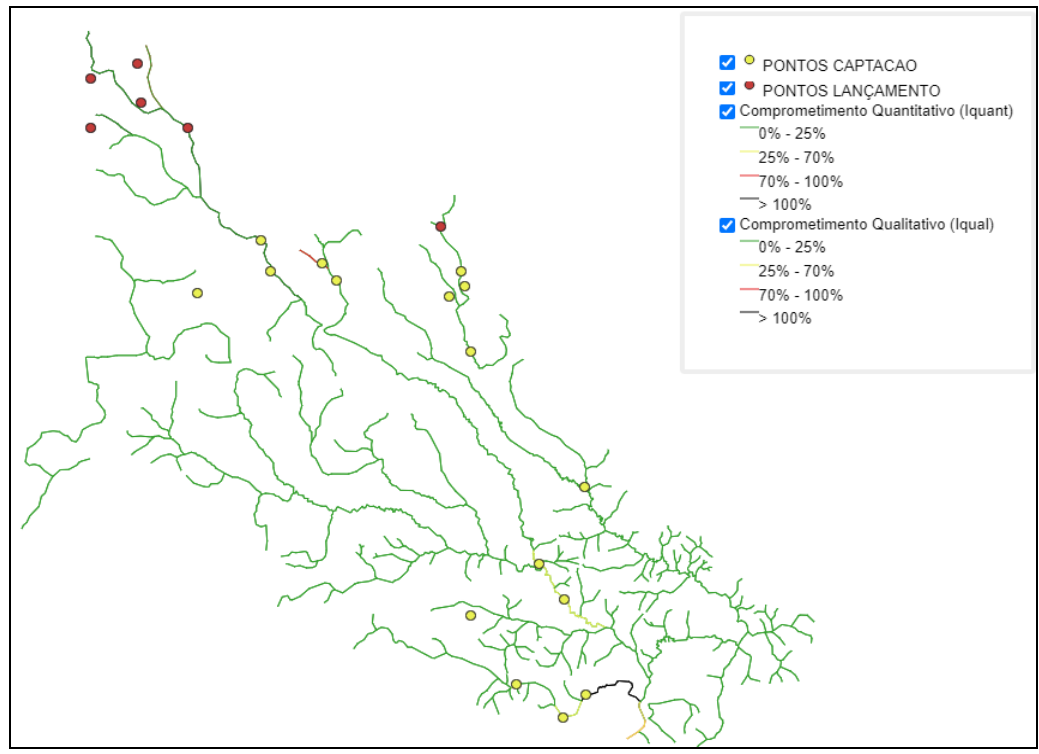

Figura 20: Exemplo de visualização das informações disponíveis para usuários externos em um mapa. Fonte: As autoras.

\section{CONCLUSÕES}

A proposta de melhoria no processo de trabalho Análise Técnica de Outorga realizado pelo órgão gestor de recursos hídricos do estado da Bahia atingiu o seu objetivo na medida em que:

- Identificou a possibilidade de ganhos em desempenho, produtividade e otimização das funções desempenhadas pelo quadro técnico do órgão gestor.

- Reduziu a quantidade de atividades manuais realizadas. Essa redução proporcionará que o processo fique mais rápido, simples, seguro e com menos falhas. 
- Apresentou inovações de metodologia e procedimentos na proposição de um SSD para outorga, considerando experiências de sistemas existentes e adaptando-o à realidade local.

As limitações identificadas para o sistema proposto foram:

- Necessidade de equipe de desenvolvimento para realizar a atualização do SEIA incluindo as propostas apresentadas.

- Necessidade de mão de obra para organizar banco de dados para alimentar o sistema.

Recomenda-se que, em conjunto com a atualização do SEIA incluindo propostas apresentadas sejam implementadas as seguintes melhorias:

- Implantação do projeto desenvolvido pela SEMA das funcionalidades de elaboração de Parecer Técnico e Portaria de Outorga de forma automatizada pela Diretoria Geral do Inema.

- Desenvolvimento de funcionalidade para relacionar processos de renovação e alteração de outorga com os processos originais.

- Desenvolvimento de projeto para viabilizar o relacionamento de processos de renovação e alteração de outorga com os processos originais.

- Desenvolvimento de SSD para captação subterrânea e integração águas superficiais e subterrâneas quando aplicável.

- Desenvolvimento de projeto de melhoria do processo Solicitação e Análise de Dispensa de Outorga com objetivo de otimizar a emissão de dispensas. Recomenda-se estabelecer critérios para definição de bacias críticas e não críticas baseado nos índices de comprometimento quantitativo e qualitativo e a partir daí automatizar a emissão de dispensas para bacias não críticas.

- Desenvolvimento de projetos de melhoria dos processos no órgão gestor de recursos hídricos do estado da Bahia com o objetivo de aprimorar o relacionamento entre dados e informações gerados pelos diversos sistemas utilizados para operacionalização dos instrumentos da Política Estatual de Recursos Hídricos (PERH).

\section{AGRADECIMENTOS}

Pelo apoio técnico científico aportado até o momento, as autoras deste artigo agradecem: ao Instituto do Meio Ambiente e Recursos Hídricos - Inema (Bahia), à Coordenação de Aperfeiçoamento de Pessoal Nível Superior - Brasil (CAPES) - Código de Financiamento 001 e ao Programa de Mestrado Profissional em Rede Nacional em Gestão e Regulação de Recursos Hídricos - ProfÁgua, Projeto CAPES/ANA AUXPE №. 2717/2015

\section{REFERÊNCIAS}

Agência Nacional de Águas - ANA. (2013). Manual de procedimentos técnicos e administrativos de outorga de direito de uso de recursos hídricos. Brasília: ANA.

Agência Nacional de Águas - ANA. (2019). Outorga dos direitos de uso de recursos hídricos (encarte Conjuntura dos Recursos Hídricos no Brasil 2019). Brasília: ANA.

Agência Nacional de Águas - ANA. (2020). Boletim Progestão № 22. Brasília, 22 de junho de 2020. Brasília: ANA. Recuperado em 20 de julho de 2021, de http://progestao.ana.gov.br/portal/progestao/destaquesuperior/boletins/boletins-2020/boletim-progestao-no-22_junho-2020.pdf

Amaro, C. A., \& Alves, M. H. (2019). Proposta de um sistema de suporte à decisão para concessão de outorgas de águas superficiais para o estado de Rondônia. In XXIII Simpósio Brasileiro de Recursos Hídricos. Foz do Iguaçu: ABRH

Association of Business Process Management Professionals International - ABPMP. (2013). Guia para o Gerenciamento de Processos de Negócio Corpo Comum de Conhecimento (BPM CBOK). Brasília: ABPM.

Bahia. Secretaria do Meio Ambiente e Recursos Hídricos. (2016). Sistematização, diagnóstico e consistência dos dados hidrológicos utilizados para definir a disponibilidade hídrica para fins de outorga no Estado da Bahia. Relatório Técnico Final das Atividades. Produto 07 - Contrato PDA № 14/2015. Programa de Desenvolvimento Ambiental, Salvador.

Brasil. (1997, 8 de janeiro). Lei no 9.433, de 8 de janeiro de 1997. Institui a Política Nacional de Recursos Hídricos, cria o Sistema Nacional de Gerenciamento de Recursos Hídricos, regulamenta o inciso XIX do art. 
21 da Constituição Federal, e altera o art. 1o da Lei no 8.001, de 13 de março de 1990, que modificou a Lei № 7.990, de 28 de dezembro de 1989. Diário Oficial [da] República Federativa do Brasil, Brasília.

Business Process Model and Notation - BPMN. (2016). Specification Recuperado em 01 de março de 2020, de http://www.bpmn.org/

Ceará. (2017). Formulário de Auto avaliação das Metas de Gestão de Aguas no âmbito do Sistema Estadual Programa de Consolidação do Pacto Nacional pela Gestão das Aguas - PROGESTAO. Recuperado em 13 de agosto de 2020, de http://www3.snirh.gov.br/portal/progestao.

Ceará. Secretaria dos Recursos Hídricos, Coordenadoria de Gestão dos Recursos Hídricos. (2008). Outorga e licença de obras hídricas. Manual de procedimentos, Fortaleza.

Colliscohnn, B. (2014). Sistema de apoio à decisão para outorga de direito de uso de recursos hídricos (Tese de doutorado). IPH/UFRGS, Porto Alegre.

Deming, W. E. (1990). Qualidade: a revolução na administração. Rio de Janeiro: Marques-Saraiva.

Departamento de Águas e Energia Elétrica - DAEE. (2012). Roteiro de Utilização SSD Outorga DAEE. São Paulo: DAEE.

Garcia, J. I. B., Schardong, A., \& Porto, R. L. L. (2018). Decision support system for optimization of permits for wastewater discharge. Revista Brasileira de Recursos Hídricos, 23.

Goiás. Secretaria de Estado de Meio Ambiente e Desenvolvimento Sustentável - SEMAD. Manual do usuário do Sistema Eletrônico de Cadastro e Solicitação de Outorga (Web Outorga). Agosto de 2019. Versão 1.0.

Heinzle, R., Gauthier, F. A. O., \& Fialho, F. A. P. (2010). Semântica nos sistemas de apoio a decisão: o estado da arte. Revista da UNIFEBE, 1(8).

Instituto do Meio Ambiente e Recursos Hídricos - INEMA. (2020). Manual do Usuário - Sistema Estadual de Informações Ambientais e de Recursos Hídricos. Salvador: INEMA. Recuperado em 13 de fevereiro de 2020, de http://sistema.seia.ba.gov.br/resources/Manual_SEIA_UE.pdf

Instituto Estadual de Meio Ambiente e Recursos Hídricos - IEMA. (2013). Nota Técnica SUORE/GRH/IEMA N 007/2013. Metodologia para análise de outorga de direito de uso de recursos hídricos utilizando o Sistema de Controle de Balanço Hídrico das Bacias Hidrográficas do Espírito Santo (SCBH-ES). Vitória: IEMA/ES.

Instituto Estadual do Ambiente - INEA. (2019). Norma Operacional NOP-INEA-37. Critérios, definições e condições para outorga de direito de uso de recursos hídricos superficiais. Revisão 0. Ato de Aprovação Resolução INEA

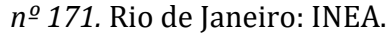

Instituto Natureza do Tocantins - NATURANTINS. (2018). Gerência de Controle de Uso dos Recursos Hídricos. Outorga de Direito de Uso de Recursos Hídricos - SAD Outorga. Recuperado em 15 de janeiro de 2019, de http://www3.snirh.gov.br/portal/progestao/destaque-superior/eventos/oficinas-de-intercambio1/outorga/palmas-2018/apresentacao-outorga-to.pdf

Julian, D. W., Hickey, J. T., Fields, W. L., Ostadrahimi, L., Maher, K. M., Barker, T. G., Hatfield, C. L., Lutz, K., Marks, C. O., Sandoval-Solis, S., \& Lund, J. R. (2015). Decision support system for water and environmental resources in the connecticut River Basin. Journal of Water Resources Planning and Management, 142(1), 1 16. http://dx.doi.org/10.1061/(ASCE)WR.1943-5452.0000538

Kharabsheh, M., Alsha'ar N. A., \& Al-Ayyoub, M. (2019). A comparative decision support systems for water resources management. International Review of Automatic Control (I.RE.A.CO.), 12(5). https://doi.org/10.15866/ireaco.v12i5.18016.

Laboratório de Sistemas de Suporte à Decisões do Departamento de Engenharia Hidráulica e Sanitária da Escola Politécnica da Universidade de São Paulo - LABSID. (2012). Manual de Utilização Do SSD OutorgaLS Plataforma generalizada para análise de concessão de outorga. São Paulo: PUC-SP.

Mato Grosso do Sul. Secretaria de Estado de Meio Ambiente e Desenvolvimento Econômico. (2015). Manual Outorga de Direito de Uso dos Recursos Hídricos. Campo Grande: SEMAS.

Oliveira, C. U. R., \& Zeilhofer, P. (2017). Sistema de Suporte à Decisão baseado em Lógica Fuzzy para Outorga de Recursos Hídricos Superficiais. In Anais do Workshop de Computação Aplicada à Gestão do Meio Ambiente e Recursos Naturais (WCAMA_CSBC), São Paulo: SBPCOPENLIB.

Pará. Secretaria de Estado de Meio Ambiente e Sustentabilidade. Diretoria de Gestão Administrativa e Financeira. Comissão Especial de Licitações. (2017). Edital de Concorrência № 001/2017-SEMAS. Contratação de serviço especializado para desenvolvimento e implantação de Sistema de Gerenciamento de Recursos Hídricos no Estado do Pará com ênfase na modernização geral dos procedimentos que envolvem a expedição de atos autorizativos de uso de recursos hídricos. Belém: SEMAS. 
Paulo, R. G. F., \& Silva, G. O. M. (2016). Critérios legais e técnicos para análise dos pleitos de outorga de direito de uso de recursos hídricos no estado da Bahia. In I Simpósio da Bacia Hidrográfica do Rio São Francisco, Juazeiro: Agência Peixe Vivo.

Pereira, M., Kayser, R. B., \& Collischonn, W. (2012). Integração do Modelo Hidrológico para Grandes Bacias MGB-IPH e Sistemas de Informação Geográfica para suporte à decisão de outorga de direito de uso da água. Revista de Gestão de Água da América Latina, 9(2), 21-33.

Porto, R. L. L., Roberto, A. N., Schardong, A., \& Méllo Júnior, A. V. (2003). Sistema de suporte a decisão para análise de sistemas de recursos hídricos. In R. C. V. Silva (Ed.), Métodos numéricos em recursos hídricos. (Cap. 2, pp. 93-240). Porto Alegre: ABRH.

Ramos, D. D., Pereira, S. B., Arai, F. K., Santos, F. A., \& Carnevali, T. O. (2017). Water seasonality in granting permits and impact of irrigation in the Dourados River basin, MS, Brazil. Revista Brasileira de Engenharia Agrícola e Ambiental, 21(7), 499-504.

Rio Grande do Sul. Secretaria de Estado do Ambiente e Desenvolvimento Sustentável. (2018). Portaria № 110 de 30 de setembro de 2018. Institui a obrigatoriedade do Sistema de Outorga - SIOUT para os procedimentos administrativos relacionados ao uso dos recursos hídricos sob a gestão do Estado do Rio Grande do Sul. Diário Oficial do Estado do Rio Grande do Sul, Porto Alegre.

Santa Catarina. Secretaria de Estado do Desenvolvimento Econômico Sustentável - SDS. Sistema de Apoio à Decisão para Planejamento do Uso dos Recursos Hídricos - SADPLAN. (2018). Manual Técnico Operacional com foco em Planejamento. Florianópolis: SADPLAN.

Schwab, K. (2016). The Fourth Industrial Revolution. Genebra: World Economic Forum.

Silva, F. F., Cardoso, E. R., Santana, A. G, Pereira, J. S., Cortizo, C. S., Cunha, R. G. L, \& Ribeiro, C. A. O. (2003). Sistema de gerenciamento de controle de outorga - SIGO - Uma aplicação na bacia do rio Paraguaçu, Bahia. In I Simpósio de Recursos Hídricos da Amazônia - I SRH, Manaus: UFR.

Silva, G. O. M., Medeiros, Y. D. P., Fontes, A. S., \& Montenegro, S. M. G. (2017). Water permit integration in the Paraguaçu River Watershed (Bahia). Revista Brasileira de Recursos Hídricos, 22. http://dx.doi.org/10.1590/2318-0331.0217170047

\section{Contribuições dos autores:}

Gisele Oliveira Mota da Silva: elaboração de texto principal a partir de seu projeto no Mestrado Profissional em Gestão e Regulação de Recursos Hídricos - ProfÁgua.

Yvonilde Dantas Pinto Medeiros: revisão do texto, indicação de artigos para revisão bibliográfica, orientação no desenvolvimento do projeto.

Andrea Sousa Fontes: revisão do texto, indicação de artigos para revisão bibliográfica, orientação no desenvolvimento do projeto. 